\title{
Building Social Resilience and Inclusion in Disasters: A Survey of Vulnerable Persons' Social Media Use
}

\author{
Vanessa Cooper \\ RMIT University, Melbourne,Australia \\ vanessa.cooper@rmit.edu.au
}

\section{Peter Hayes}

RMIT University, Melbourne, Australia

\section{Stan Karanasios}

University of Queensland, St. Lucia, Australia

\section{Abstract}

Social media (SM) is increasingly used to reach out to populations for preparedness and response to disasters. Given the disproportionate impacts of disasters on vulnerable populations (e.g., older persons, persons socially/geographically isolated, persons living with disabilities, persons of low socio-economic means) in this study we focus specifically on the attitudes, needs and future plans of vulnerable persons towards accessing and sharing information via SM during extreme weather events. Advancing understanding in this area is important as there is growing evidence that people who may be described as more vulnerable may have different communication needs and less access to disaster related information and technologies. We present the results of a survey of 215 vulnerable persons in Victoria, Australia. Rather than consider vulnerable persons as a homogenous group, we examine how persons with different vulnerabilities perceive SM for accessing and sharing information in the context of disasters and report findings which challenge prevalent assumptions about vulnerable persons and SM. Overall we find that vulnerable persons are not passive recipients of support during disasters but have self-awareness, a strong desire to receive information and the capacity to usefully contribute to the provision of reliable information via SM. With a view to improving outcomes for vulnerable persons in disasters we offer an agenda for future research.

Keywords: Social media, vulnerable persons, disaster management, communication, community resilience.

\section{Introduction}

Over the last 15 years social media (SM) has grown to become a significant part of many peoples' lives and has had a profound impact on the way in which society functions and communicates. SM incorporates social networking, forums, blogs and micro-blogs, social book-marking, collaborative document creation and the sharing of audio, photographic and video files (Alexander, 2014). SM represents a significant technological innovation and has transformed digital information sharing and networking (Panagiotopoulos, Barnett, Bigdeli, \& Sams, 2016). Organisations are increasingly relying on SM channels to inform, influence, and interact with the community. This is certainly the case when disaster events occur (Gill, Alam, \& Eustace, 2015). Across the globe there are numerous examples where SM platforms have been reported to help keep people informed and safe before, during and after wildfires/bushfires (Abedin \& Babar, 2018), floods (Al-Saggaf \& Simmons, 2015), hurricanes (Kryvasheyeu et al., 2016), snowstorms (Panagiotopoulos et al., 2016) and tsunamis and 
earthquakes (Peary, Shaw, \& Takeuchi, 2012). Yet while emergency response organisations (EROs) and other actors increasingly understand the value of SM in disasters, and there is a growing body of literature in this area (e.g., Al-Saggaf \& Simmons, 2015; Elbanna, Bunker, Levine, \& Sleigh, 2019; Panagiotopoulos et al., 2016), to date there has been limited research undertaken to understand how SM is being used to connect to parts of the community which may be considered more vulnerable. Advancing research in this area is important as there is growing evidence that people who may be described as more vulnerable may have different communication needs and less access to disaster related information and technologies (Howard, Agllias, Bevis, \& Blakemore, 2017) and suffer disproportionately during and post large-scale disasters (IFRC, 2005, 2013).

The term vulnerability originates from the Latin word 'vulnerare' meaning "to wound" and generally indicates the degree of exposure to the possibility of disruption or harm. In investigating the complex concept of vulnerability, researchers have developed a plethora of models, metrics and tools to depict, measure and assess vulnerability (e.g., Cutter, 1996; Luna, 2014; Zebardast, 2013). Yet vulnerability remains an "elusive and slippery concept" (Luna, 2018) which is defined and used differently across disciplines (Alwang, Siegel, \& Jorgensen, 2001). While acknowledging the complexity and range of approaches to defining and categorizing vulnerable persons (e.g. Eakin \& Luers, 2006; Wisner, 2004), and the difficulty in defining vulnerability in multi-disciplinary contexts such as disasters (Enang et al., 2019), the United Nations International Strategy for Disaster Reduction defines vulnerability as, "The conditions determined by physical, social, economic and environmental factors or processes which increase the susceptibility of an individual, a community, assets or systems to the impacts of hazards" (UNISDR, 2016, p. 41).

We focus on older persons (aged 60+), those who are geographically and/or socially isolated (GSI) (e.g., live in a remote community and/or live alone in an urban area), people who suffer from physical limitations (PL) in terms of physical functioning, mobility, dexterity and those of low socio-economic (LSE) means. This is because these people are frequently identified as amongst the most vulnerable people in the disaster literature. The elderly were overrepresented in those people who were impacted by the 2005 Hurricane Katrina in the USA (Gibson \& Hayunga, 2006), 2011 earthquake and tsunami in Japan (Nakahara \& Ichikawa, 2013) and, based on figures to date, during the current global coronavirus pandemic (COVID19) (Onder, Rezza, \& Brusaferro, 2020). Examples where isolation has increased the impact of disasters include Chicago's 1995 heatwave where a disproportionate number of deaths occurred among people living alone (Smoyer Tomic, 2003). In Australia, it has been identified that residing in a rural area substantially increases the risk of natural disasters and living with the ongoing threat of natural disasters can have adverse psychosocial, mental health and community impacts (Morrissey \& Reser, 2007). People living with disabilities were more than twice as likely to have been injured during Tropical Cyclone Pam in Vanuatu (Bakera et al., 2017) and using data from Japan, persons living with disabilities are predicted to be four times more likely to die when a disaster strikes (OHCHR, 2015). One's socio-economic status can influence disaster awareness levels (Teo, Goonetilleke, Ahankoob, Deilami, \& Lawie, 2018), ability to absorb losses and resilience towards hazards and impacts through lack of access to insurance, social safety nets and entitlement programs (Cutter, Boruff, \& Shirley, 2003). Disasters such as Hurricane Katrina in 2005 (Masozera, Bailey, \& Kerchner, 2007) and global pandemics such as COVID-19 (Buheji et al., 2020) illustrate how people of LSE means can be more vulnerable to disasters. 
To ensure SM use better supports vulnerable people during disasters, an important first step is to identify vulnerable persons' attitudes, needs and future plans to use SM to access and share information in these critical contexts. Several surveys on the use of SM in the disaster context have been undertaken (e.g., American Red Cross, 2012; Canadian Red Cross, 2012; Reuter, Kaufhold, Schmid, Spielhofer, \& Hahne, 2019; Reuter \& Spielhofer, 2017) but the extent these studies are generalisable to more vulnerable populations is unclear. Our study addresses the following research question:

"What are the attitudes, needs and future plans of vulnerable persons towards accessing and sharing information via SM during extreme weather events?"

To answer this question, we report the results of an online survey administered to vulnerable persons in the Australian state of Victoria that explores their attitudes, needs and future plans to use SM to access and share information during extreme weather events. For the empirical component of our study, we focus on "extreme weather events" as this terminology was predicted to be more relevant to survey respondents than "emergencies" by interview and focus group participants (see Section 3.1). Extreme weather events are generally described by a range of attributes including the rate of occurrence (rarity), magnitude (intensity), temporal duration and timing, spatial structure and multivariate dependencies (Stephenson, Diaz, \& Murnane, 2008). In our study we are interested in extreme weather events that are consistent with the local hazard profile of Victoria, Australia - namely, floods, storms, fire and heatwaves.

The remainder of the paper is structured as follows. In Section 2 we review related research and in Section 3 we describe our research method. We report our findings in Section 4. In Section 5 we discuss the findings against extant literature. In Section 6 we present our contributions to research and practice, offer an agenda for future research and acknowledge the limitations of the study. In Section 7 we conclude our paper.

\section{Related work}

In this section we examine the literature on the use of SM in disasters (Section 2.1). The scant literature on SM use by vulnerable persons in disasters is also considered (Section 2.2).

\subsection{SM use in disasters}

SM is a relatively new phenomenon and consequently, there is limited research on SM use in disasters predating 2007 (Alexander, 2014). Nonetheless the use of SM in disasters is increasing and researchers have shown a growing interest in the area. In this section we focus on five key themes addressed in the literature.

\subsubsection{How SM is used in disasters}

A body of research has focused on how SM is used in disasters (Alexander, 2014; Kim \& Hastak, 2018). Based on a review of prior research and two case studies (a volcano eruption in Iceland and a mass panic at a music festival in Germany) four categories of SM use in crisis situations are outlined by Reuter, Marx, and Pipek (2012): From organisations to the public addresses the integration of SM into classical crisis communication activities such as EROs' use of Facebook to provide broadcast messages to members of the public. From the public to the public addresses the domain of self-help communities whereby SM can provide a platform for community groups that allow members of the public to ask questions, express their needs and fears, and offer assistance and support to others. From the public to organisations captures the 
integration of citizen generated content and the various ways in which this can be analysed and used by organisations. From organisations to organisations addresses inter-organisational crisis management activities whereby SM can support a range of organisational actors in disasters to share information, communicate and network to improve inter-organisational awareness and informal processes.

\subsubsection{Community initiated SM groups in disasters}

Literature has focused on community initiated groups and how SM group administrators disseminate information, the questions asked by group members and community dynamics and influences (Bird, Ling, \& Haynes, 2012; Kulemeka, 2014). For example, Bird et al. (2012) studied the emergence of community Facebook groups during the 2010/2011 Queensland and Victorian floods. They identified through an online survey that group administrators sourced information from formal organisations (e.g., EROs, local governments, Bureau of Meteorology, news media) and published information from citizens in near-real time. Group members posted information and questions, requested and received help and advice, while travellers posted and received information on road closures and flooding. Kulemeka (2014) undertook a content analysis of a community Facebook group comprised of people affected by the 2014 fire at the Hazelwood Coal Mine in Victoria, Australia and compared this to an Internet forum on Tianya following the 2008 earthquake in China (Qu, Wu, \& Wang, 2009). Despite differences in culture, location and disaster events, members of both communities used SM to share or seek information, support each other, express emotion, try to make sense of events and organise action. Differences were evident in the types of threads occurring, when threads were created and preferences users showed toward threads (Kulemeka, 2014).

\subsubsection{Organisational integration of SM in disasters}

From an organisational perspective, research has investigated the way organisations have integrated SM into their internal operations. For instance, the Red Cross created the Ready2Help platform that matched individuals needing help with people who could offer it (Schmidt, Wolbers, Ferguson, \& Boersma, 2017). Further examples include crowdsourcing and mapping platforms (e.g., QuakeMap used in the 2015 Nepalese earthquake) that guide relief efforts (Wolbers, Boersma, Ferguson, Mulder, \& Groenewegen, 2016). The complexity of the organisational landscape in disasters has been examined in light of the emergence of digital networks. This research suggests the convergence of the organisational boundaries and activities, as well as the convergence of physical and online spaces (Hughes \& Tapia, 2015; Schmidt et al., 2017). The need to carefully consider how SM is integrated with organisations' traditional communication strategies and technologies has been highlighted (ApplebyArnold, Brockdorff, Fallou, \& Bossu, 2019; Elbanna et al., 2019). As the interactions and relationships between organisations, individuals and technology move away from the bureaucratic, top-down logic, they become more complex and may result in behaviour that is difficult to predict (Luna \& Pennock, 2018). For example, EROs often need to contend with "flash volunteers" and "disaster tourists" and the tensions these phenomena cause to their traditional prevention, preparedness, response and recovery (PPRR) protocols (Elbanna et al., 2019). Others have investigated the attitudes of emergency services personnel towards SM and their perceptions of organisations' current and future SM use (Reuter, Kaufhold, Spahr, Spielhofer, \& Hahne, 2020). Recognising the complexities that SM can bring, guidelines have been developed to prevent chaotic use of SM in disasters (Kaufhold, Gizikis, Reuter, Habdank, \& Grinko, 2019). 


\subsubsection{Information-related issues for SM in disasters}

Information-related issues are critical in SM and disasters as the provision of transparent information can facilitate community resilience (Cohen, Goldberg, Lahad, \& AharonsonDaniel, 2017; Cooper, Fairbrother, Elliott, Walker, \& Ch'ng, 2020). There has been a push towards the use of SM in disasters to transmit fast and clear information and to collect information from at-risk populations. For example, following the Japan Tsunami, platforms such as Twitter, Mixi, Facebook and Google's Person Finder served as a point where requests for assistance could be made, enabled the dissemination of information such as the location of local evacuation centres and provided a way for survivors to locate friends and family and let people know that were safe (Appleby, 2013). Nonetheless, disasters are characterised by several types of information challenges that SM does not necessarily resolve. For instance, there can be challenges surrounding the choice of the most appropriate channels for distributing and sharing information, the volume of information and the selection of the format and content of information (Gill et al., 2015; Hagar, 2013; Pang, Karanasios, \& Anwar, 2020; Schmidt \& Galea, 2013). There are challenges surrounding perceptions of the reliability and veracity of information on SM whereby agencies and citizens are afraid that social networks will produce inaccurate information of dubious provenance (Elbanna et al., 2019; Goolsby, 2010; Palen, Vieweg, \& Anderson, 2011). Other research, however, suggests that harmful and inaccurate rumours are not particularly enhanced by SM because with mass participation, false rumours are easily corrected by knowledgeable people (Bird et al., 2012; Hjorth \& Kim, 2011). The predominant use of SM by organisations is to broadcast generic information rather than provide targeted information (Karanasios, Cooper, Hayes, \& Adrot, 2019). The lack of two-way communication has been problematic as those at risk in a disaster may lack specific advice about what actions their household should take to protect themselves and their property (Poblet-Balcell, Cooper, \& Karanasios, 2018).

\subsubsection{Sentiment and network analysis via SM in disasters}

Research in SM has focused on sentiment and network analysis. SM provides people with a unique platform to express their thoughts and feelings publicly during times of disasters (Qiu, $\mathrm{Xu}$, Wang, \& Gu, 2020). Using data on Twitter referring to the Kashmir floods, Kaur and Kumar (2015) develop a model to assist authorities strategize during disaster based on public sentiments. Kim and Hastak (2018) leveraged data from Facebook in the city of Baton Rouge after the 2016 Louisiana flood to analyse the emergent networks after the flood. The researchers were able to explore connections and patterns based on aggregated interactions on Facebook, highlight the social roles and key players in the network and analyse the content of posts (Kim \& Hastak, 2018). With the volume of data being generated on tools such as Facebook and Twitter it is likely that automated approaches to analyse data will grow.

\subsection{SM use by vulnerable persons in disasters}

Post-disaster reports across the globe have highlighted the disproportionate impact and number of fatalities amongst groups defined as 'vulnerable' (Deacon, 2018; Nakahara \& Ichikawa, 2013). Typically, academic research that addresses disaster and SM treats individuals and communities as homogenous and there is relatively little research that has examined the use of SM by vulnerable persons in disasters specifically. In this section we highlight some of the exceptions in the literature.

The use of SM by people with disabilities during disasters and public emergencies was examined by Morris, Mueller, and Jones (2014). The US-based study involved a survey of 
people with hearing, vision, cognitive, mobility, dexterity, and speech limitations and found that these people are at greater risk during emergencies because they may not receive or understand emergency alert information or may not be able to take the required actions (Morris et al., 2014). The study highlights that the use of SM for accessing and sharing information during emergencies is relatively low among the respondents and that differences in SM usage across people with different disability types are minimal, the exception being people who are deaf or who have speech limitations who use SM more than people with other disabilities. It is inferred from the findings that disaster communication strategies should be tailored to consider the diverse needs of people living with a variety of disabilities. Other studies point to the lack of tailored information on SM for vulnerable persons in disasters. In an analysis of information posted to Twitter and Facebook about extreme weather events in Victoria, Australia, Poblet-Balcell et al. (2018) identified there were few examples where the posts targeted vulnerable groups such as older persons, those socially/geographically isolated, people with disabilities and refugee/recent migrant communities - instead, SM was used to raise awareness of the need to check-in with others.

Some studies that have focused on information behaviours of vulnerable persons during disasters, and while SM was not the primary focus, have offered some insight into vulnerable persons' SM usage. Through a survey of residents of a local council area in Southeast Queensland that had experienced multiple natural hazards (predominately floods and bushfires) in recent years, Teo et al. (2018) studied the disaster information seeking needs and preferences of people from LSE backgrounds and how this affected their level of disaster awareness. The study revealed that television $(60 \%)$ was the most trusted information source for both people from LSE and non-LSE backgrounds whereas SM did not feature highly for respondents from either background-with Facebook, Twitter and other SM considered a trusted source for disaster information by $18 \%, 2 \%$ and $8 \%$ of respondents respectively. This suggests that people from both LSE and non-LSE backgrounds still prefer traditional media to acquire disaster related news. Howard et al. (2017) report a series of focus groups undertaken in regional Australia on the communication channels used by vulnerable people to prepare for and respond to natural disasters. In focusing on older people, people with disabilities, culturally and linguistically diverse populations, families with young children and people from low-income households they identify that use of specific communication methods was attributable to membership of specific population groups. In terms of preferences for SM, it was found families with young children relied more on mobile phone apps, SM and websites for information on natural disasters whereas older people listen to the radio or expect phone calls on their landline (Howard et al., 2017).

Other studies examine the use of SM in disasters and during the analysis, by considering the demographic details of participants, offer insight into how people who might potentially be considered vulnerable, use SM. For example, Feldman et al. (2016) analyse a survey of residents in Newport Beach California to identify the ways in which people prefer to receive information about flood risks. By considering a range of socio-economic characteristics they identify that older persons prefer to use traditional media (TV, radio, newspaper, printed material, websites) when compared to SM sources (e.g., Facebook and Twitter) and expressed little desire to use SM in the future. Studies such as this which reveal the communication preferences of different groups are important as the effectiveness of risk communication has been found to be linked to factors that affect an individual's capacity to access relevant information. 
We now outline the methods we adopted to answer our research question.

\section{Methods}

We first focus on the survey design (Section 3.1) and describe the characteristics of participants (Section 3.2). This is followed by a description of the analysis process (Section 3.3).

\subsection{Survey Design}

The aim of the survey was to identify the attitudes, needs and future plans of vulnerable persons to use SM to access and share information in the context of extreme weather events. The design of the survey was informed by extant research on SM use by vulnerable persons in disasters (Section 2) and a series of semi-structured interviews and two focus groups, undertaken as part of a wider study, with persons aged 60+, living with PL, of LSE means as well as GSI persons. In total 47 perspectives of vulnerable persons from rural and metropolitan areas of Victoria, Australia were included in the individual interviews and focus groups. Participants were asked about how they obtained information during disasters, the digital tools they used (including SM), the types of information sought and shared, and their attitudes towards various information providers and communication channels. The main themes identified from these interviews and focus groups related to: ICT and non-ICT information sources; digital technology and SM use patterns (in general and in relation to disasters); awareness of emergency services' use of SM; trust and attitudes towards SM; and the important role of informal community networks and relationships. Additional details pertaining to the interviews and focus groups, including participant recruitment, the interview protocol, data analysis procedures and findings can be found in Karanasios, Cooper, Adrot \& Mercieca (2020).

The findings of the interviews and focus groups confirmed the existing instrument developed by Reuter and Spielhofer (2017) as relevant for our study. We adapted the instrument to include additional questions relating to: qualifying and demographic information; the various technology devices used by vulnerable persons; how much time vulnerable people spend using SM (typically and during extreme weather events); information needs; and perceptions on the helpfulness of information on SM provided by different types of organisations. As noted, the importance of informal networks and relationships as a source of information and support emerged as a key theme from the interviews and focus groups. Consequently, we included a set of questions to identify whether and how vulnerable persons use information from SM provided to them indirectly (e.g., via friends and family). Adding these questions increased the length of our survey, so several questions from the original instrument deemed less relevant to our research question were removed to minimise participant fatigue (i.e., questions on the downloading of smartphone apps and questions relating to working or volunteering in emergency services). We also changed the wording of the questions. For example, we revised questions to focus on "extreme weather events" rather than "emergencies". The resulting instrument employed quantitative and qualitative methods to generate descriptive statistical results and elicit reasons for participants' answers. The instrument is provided in Appendix One.

The survey was administered by Qualtrics ${ }^{1}$ who sent a link to the online survey to people residing in Victoria who report to have used SM to search or share information during an

\footnotetext{
${ }^{1}$ www.qualtrics.com last accessed 12th July 2021.
} 
extreme weather event, and who also identify as belonging to different vulnerable groups (i.e., aged 60+, GSI, living with PL and/or of LSE means).

\subsection{Characteristics of survey participants}

We collected 215 survey responses. The majority of participants (77.7\%) reported to belong to one vulnerability group, with $15.8 \%$ reporting to belong to two vulnerable groups, $4.7 \%$ reporting to belong to three vulnerable groups and $1.9 \%$ belonging to four vulnerable groups. Respondents were from different national backgrounds, namely, Australian (75.4\%), Asian $(9.3 \%)$, European $(8.4 \%)$, American $(2.3 \%)$ and African $(0.9 \%)$, however, most were from an English-speaking background (75.0\%). Respondents included women $(54.0 \%)$, men $(45.6 \%)$ and other $(0.5 \%)$ across diverse age groups but with around half $(52.6 \%)$ of the respondents being 22-39 years old (Figure 1).

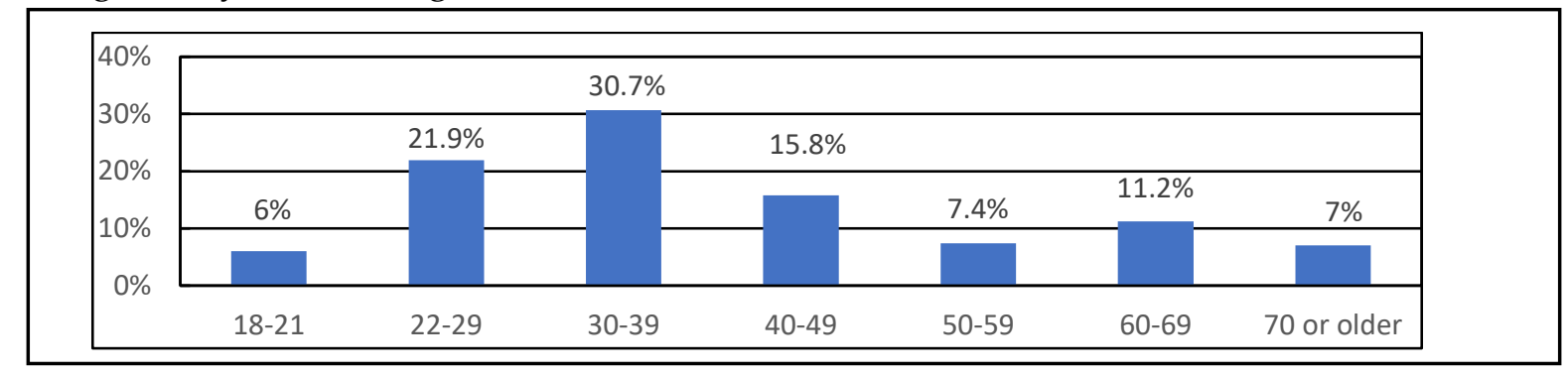

Figure 1. Age profile of participants

The highest level of formal education completed by most participants was High School (33.5\%) or a Bachelor's Degree (27.4\%). Respondents live in a variety of household types with the most common type comprising families with children $(40.5 \%)$ and $33.5 \%$ of respondents having children under the age of 18 . The employment status of participants included full-time $(31.6 \%)$, part-time $(15.9 \%)$, casual $(7.4 \%)$, homemaker $(7.4 \%)$, retired $(10.2 \%)$, pensioner $(5.2 \%)$, selfemployed (5.1\%) and unemployed (14\%).

\subsection{Survey analysis}

The survey was analysed using quantitative and qualitative techniques. For the initial quantitative analysis, the survey data was extracted and initially analysed using Excel. Basic frequencies for each question and cross-tabulations were undertaken to identify any significant differences across types of respondents. The response format for the quantitative items in the survey generally comprised a four or five-point Likert scale such as: never, seldom, sometimes, and often; or strongly disagree, disagree, neither agree/disagree, agree, and strongly agree. This type of data is ordinal and thus nonparametric methods are better suited (Kraska-Miller, 2013). To identify any differences based on vulnerability type (i.e., 60+, LSE, PL, GSI), we used SPSS 25 to complete a series of Kruskal-Wallis H one-way analysis of variance (ANOVA) tests (Chan \& Walmsley, 1997). The Kruskal-Wallis test identifies if there are differences among three or more groups but does not identify which groups are different. To ascertain this, we used a series of post hoc paired Mann-Whitney $U$ tests (also known as the Wilcoxon rank sum test), to determine which groups were different from others (Mann \& Whitney, 1947; Wilcoxon, 1945). For this analysis we included the 167 responses where respondents reported only one vulnerability type to ensure the condition of independence was met. Summary tables for the quantitative results are in Appendix Two. 
For the qualitative analysis, responses to open-ended questions were analysed in Excel based on an inductive approach. Two researchers analysed the responses to the open-ended questions and assigned participant statements to open code categories (Thomas, 2006). Through this process we obtained an overview of the relevant themes before focusing on the themes which help address our research question. As participant responses to the open-ended questions were typically brief, in the analysis presented here we summarise the high-level themes which emerged from each open-ended question and supplement this with participant quotes.

\section{Empirical results}

\subsection{Current use of technology and views towards SM}

Respondents were asked about their use of technology devices (Figure 2). The results show that smartphones are the most frequently used device with $78.1 \%$ of respondents reporting they used smartphones often. Respondents also reported that they often used laptops $(65.6 \%)$ and desktop computers (51.6\%). Tablets were used often by $30.7 \%$ of respondents, with $29.8 \%$ reporting they used tablets sometimes. Regular (non-Internet enabled) mobile phones were not used by $58.1 \%$ of respondents. Other technologies used included gaming consoles (5) and smart TVs (8). Of the five types of technology, only smartphones were used significantly differently by respondents with differing vulnerabilities $(\chi 2(3, n=167)=11.002, p<.012)$. Specifically, those aged 60+ were significantly less likely to use smartphones than LSE or GSI respondents.

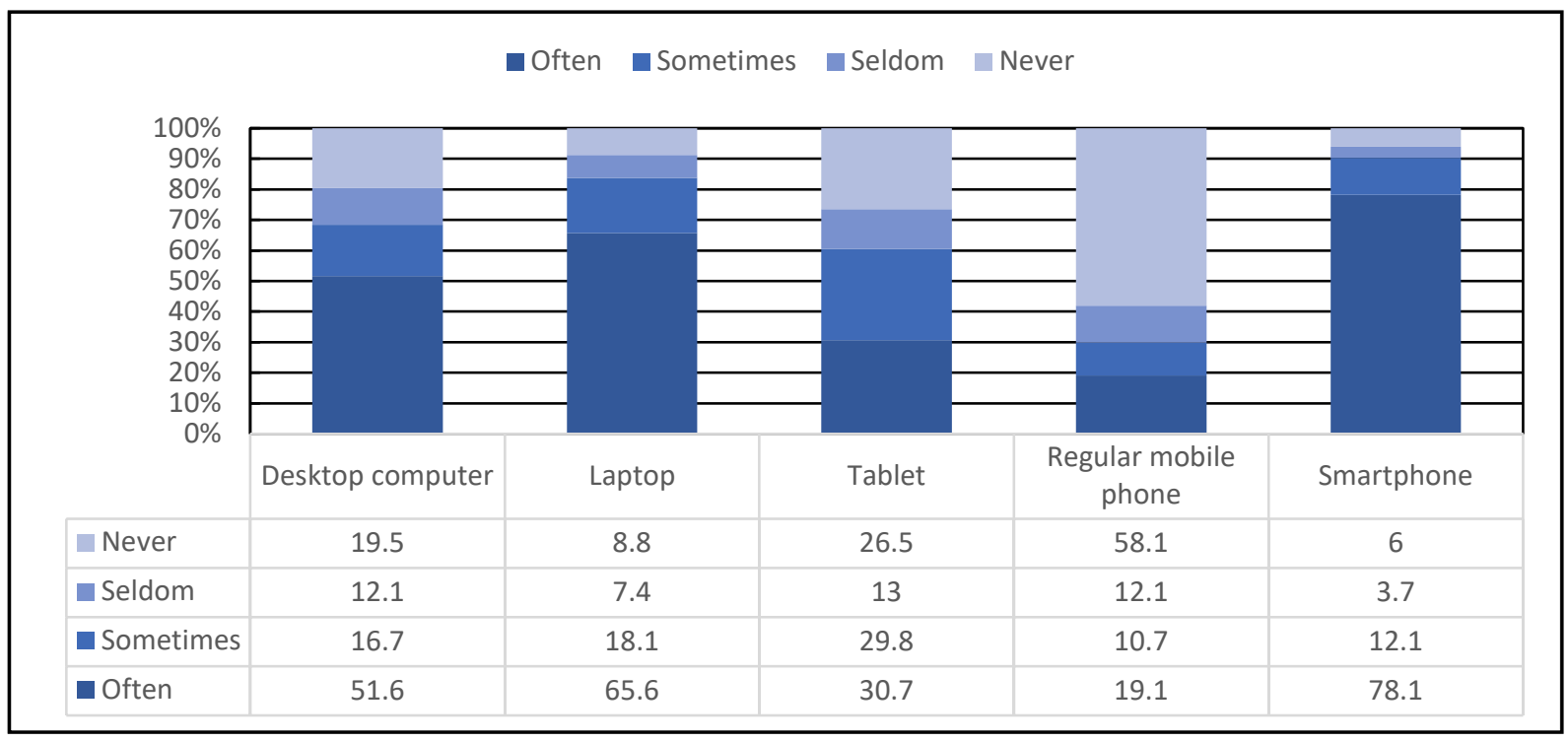

Figure 2. Common use of different technology devices

Figure 3 reports respondents' use of different SM applications. Facebook is by far the most frequently used type of SM, with 70.2\% reporting they used Facebook often. Many also used YouTube often (48.8\%), or at least sometimes (31.2\%). Some SM applications were not popular amongst respondents. Many never used Twitter (43.3\%), blogs (41.4\%), chat tools $(40.9 \%)$ or Instagram (39.1\%). Several participants identified they used 'other' SM applications such as Reddit (5) and Snapchat (7). Four of the six SM applications (i.e., Twitter, Instagram, YouTube and chat tools) were used significantly differently based on the type of vulnerability reported. Respondents aged 60+ were significantly less likely to use: (i) Twitter than GSI respondents, 
(ii) Instagram than LSE and GSI respondents, (iii) YouTube than LSE and GSI respondents, and (iv) chat tools than GSI respondents.

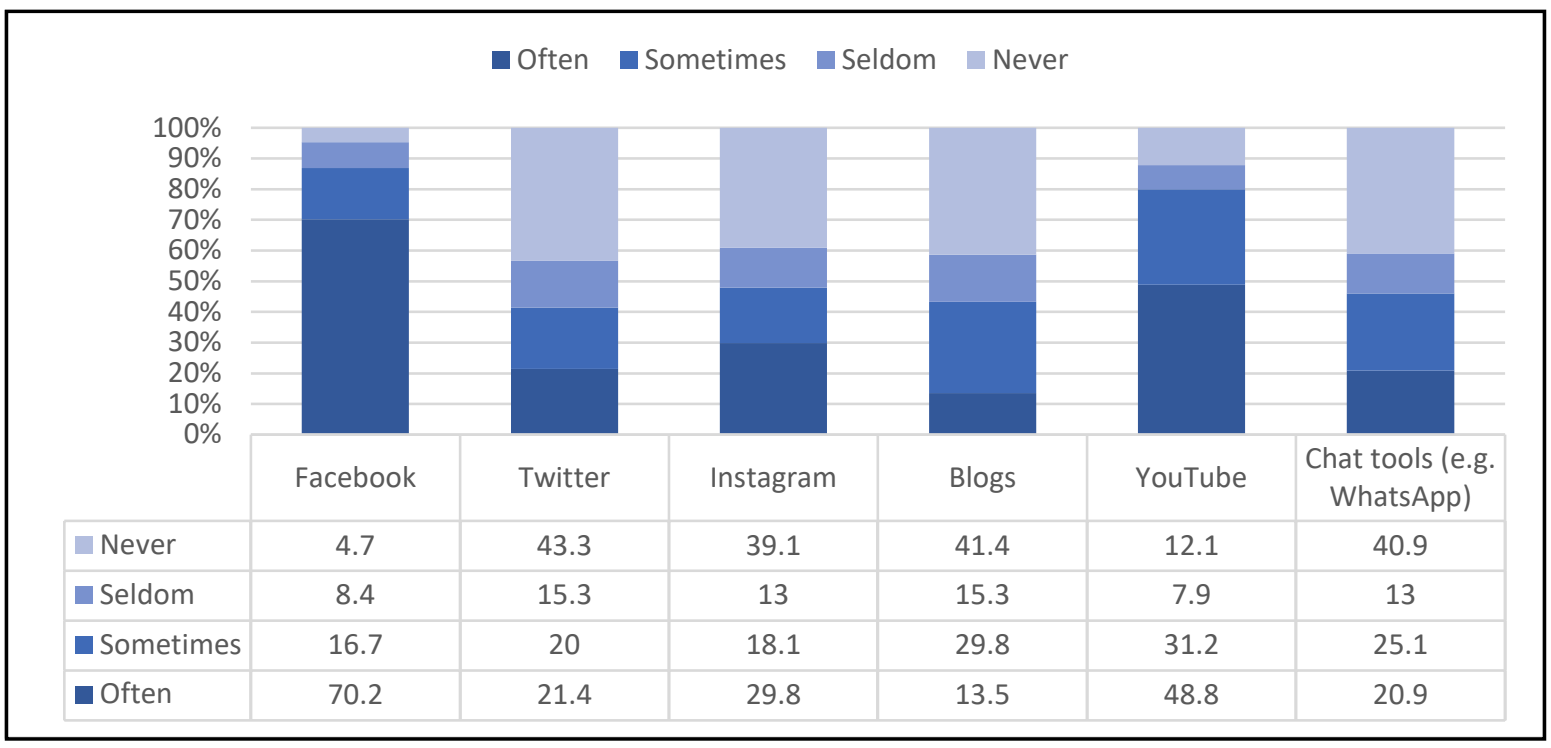

Figure 3. Current use of different SM applications

Most respondents either strongly agreed (42.3\%) or agreed (34.4\%) that they use SM very often in their private lives, with $61.4 \%$ regularly posting messages on SM (Figure 4). Most held the view that their friends also use SM to keep in touch (83.3\%). The majority of respondents $(86.9 \%)$ thought that it is important for emergency services to use SM with $61.4 \%$ reporting that they would not trust messages on SM, apart from those posted by official sources. Around one-third (31.6\%) strongly agreed or agreed that emergency services should not trust information on SM. In contrast, almost another third (27.0\%) strongly disagreed or disagreed that emergency services should not trust information on SM. Respondents from differing vulnerability groups responded significantly differently to four of the six items on SM use and trust towards SM. The four items concerned were: In my private life, I use SM very often; I regularly post messages on SM such as Twitter, Facebook or Instagram; Most of my friends use SM to keep in touch; Emergency services should not trust information on SM. Respondents aged 60+ were significantly less likely to: (i) use SM than LSE, PL, and GSI respondents, (ii) post messages on SM than LSE and GSI respondents, and (iii) perceive their friends use SM to stay in touch than LSE and GSI respondents. The fourth item asked respondents whether emergency services should not trust SM information. This reverse scored item was recoded so that a higher participant score indicates greater trust. GSI respondents were significantly more likely to believe emergency services should trust information on SM information than respondents aged $60+$ years and from LSE backgrounds.

Awareness about existing safety services provided on Twitter and Facebook varied. Only $29.8 \%$ of respondents reported to be very aware of Facebook Safety Checks and $20 \%$ being very aware of Twitter Alerts. Knowledge of these SM tools were significantly different by type of vulnerability. GSI and LSE respondents were more aware of these SM tools than those aged $60+$.

\section{2 $\mathrm{SM}$ as an information source during disasters}

When asked which communication channels they have used to get information about an extreme weather event, SM was the second most common channel used (73\%) behind TV 
(87\%). Online news (72\%) was a common source of information, followed by local radio (61\%), online sites (59\%), text messages (56\%) and mobile apps (45\%).

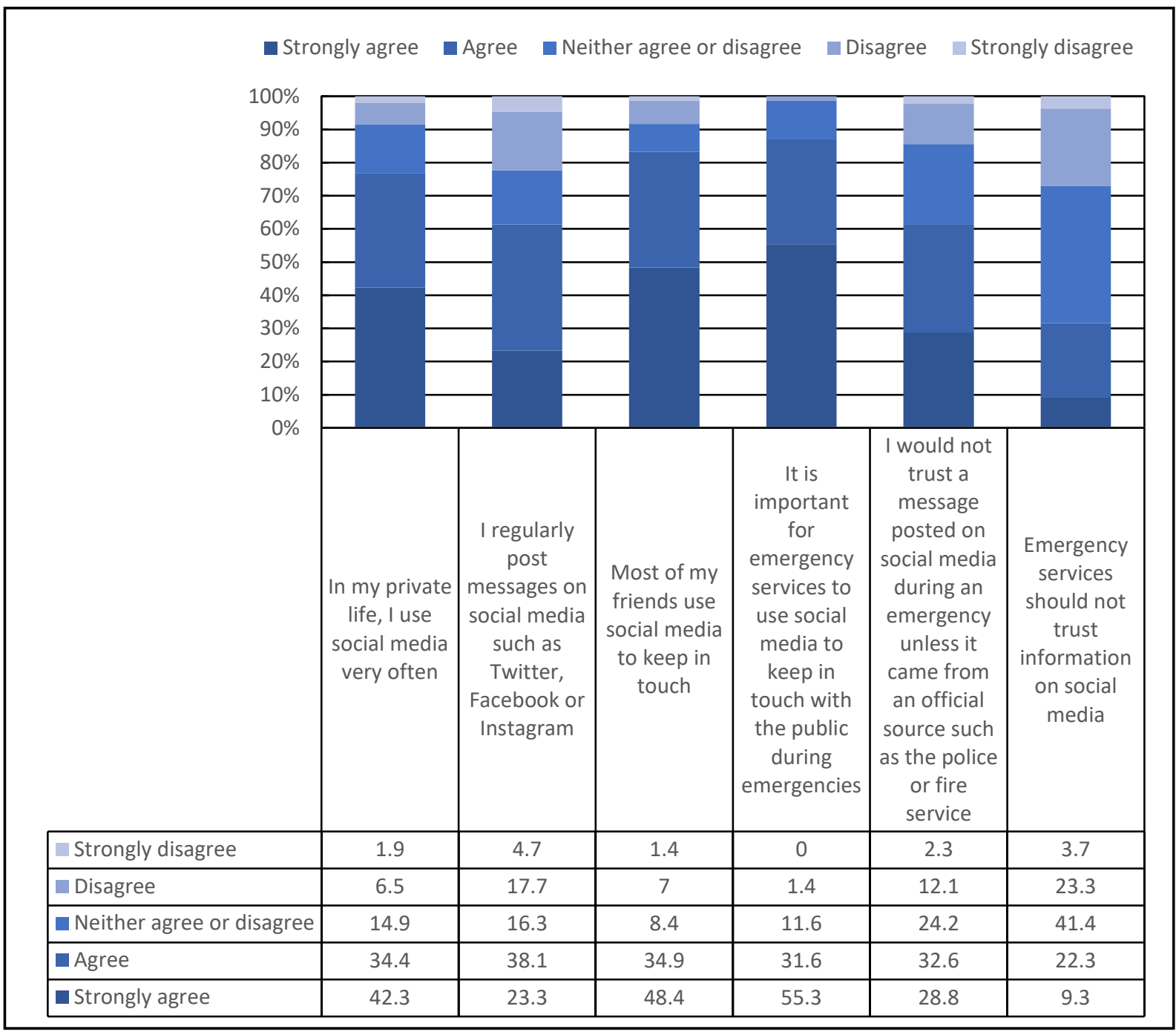

Figure 4. Use and trust of SM

We were interested in how much time respondents actively spend on SM per day during an extreme weather event compared to the time they actively spend on SM on a typical day. There were 118 (54.9\%) respondents who reported that they actively use SM more during extreme weather events when compared to a typical day. There were $82(38.1 \%)$ who reported that they are less active on SM during extreme weather events and $15(7.0 \%)$ who reported to be active on SM for the same amount of time under both conditions.

Respondents reported using SM to find out information on a variety of topics during an extreme weather event (Figure 5). Most reported they had looked for information about weather conditions or warnings $(85 \%)$, damage caused by an event $(66 \%)$ or road or traffic conditions (65\%). Many reported they had also used SM to find out the location or status of friends or family (55\%). Further, almost half the respondents used SM to find information about how others were coping with the extreme weather event $(49 \%)$, what to do to keep yourself safe $(49 \%)$ and to locate eyewitness videos or photographs $(47 \%)$. 


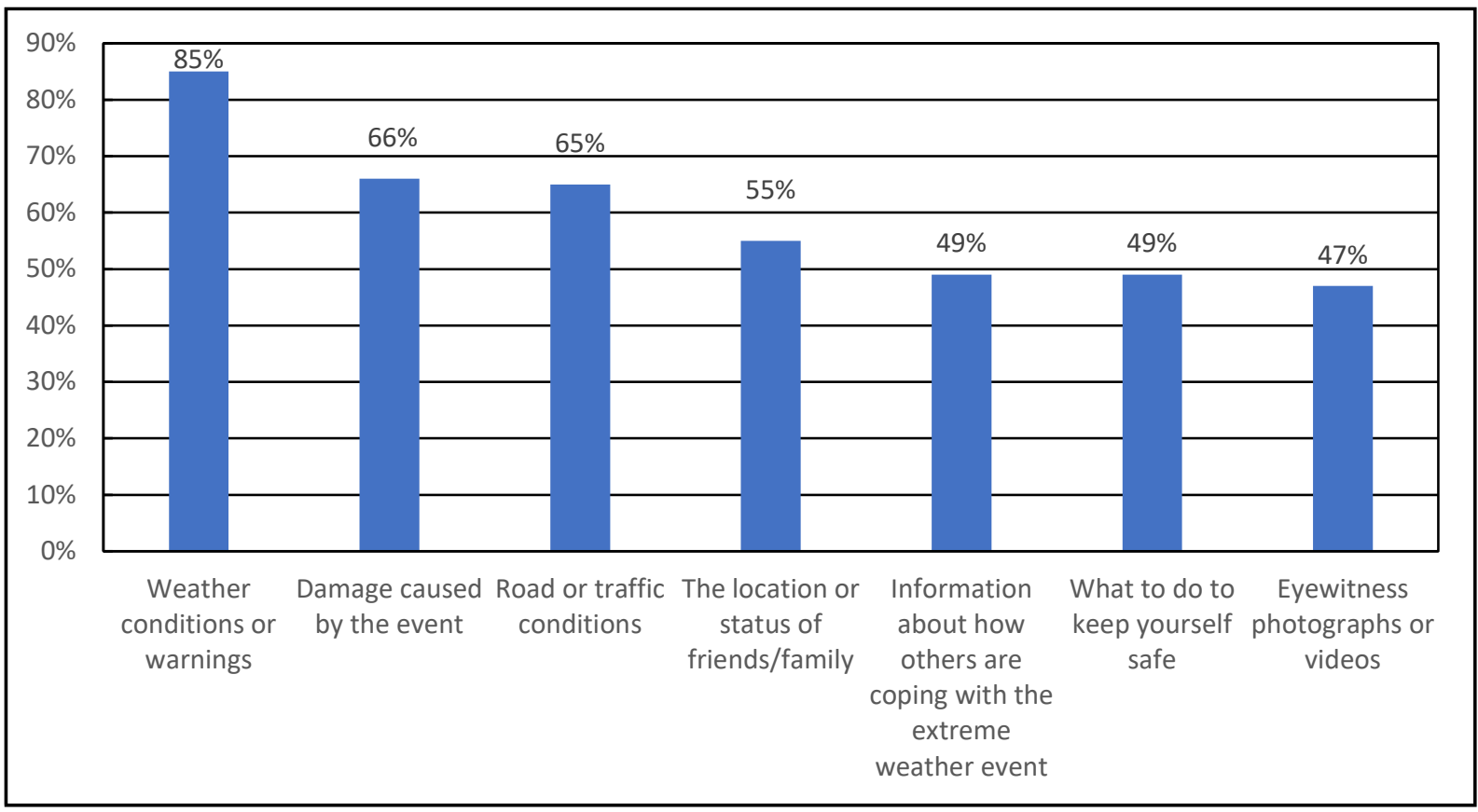

Figure 5. Types of information about extreme weather events sought using SM

We asked respondents how helpful they found the information they sought about an extreme weather event from a range of organisations using SM (Figure 6). It was anticipated this might not only illuminate the information preferences of vulnerable persons but reveal those organisations that might usefully review the information they provide to increase its relevance to different vulnerable groups. Results showed that the majority of respondents considered the information sought from EROs (70.7\%) and government agencies $(64.1 \%)$ as either extremely helpful or very helpful. A relatively high proportion considered the information sought from local online groups (49.3\%), NGOs (44.1\%), local community groups (38.6\%) and local government $(37.6 \%)$ as extremely helpful or very helpful. Some reported that information from local community groups (18.1\%) and NGOs (11.6\%) was not applicable to them.

For three of the six types of organisations (i.e., EROs, local community groups and local online groups) the level of perceived helpfulness was significantly different by type of vulnerability. GSI respondents rated the perceived helpfulness of information they sought via SM from different EROs more highly than LSE and PL respondents. A similar pattern was found for local community groups and local online groups except that GSI respondents only had more positive perceptions of the helpfulness of the information they sought via SM from these organisation than PL respondents.

Most respondents (88.4\%) indicated that it was very likely or quite likely that they would use $\mathrm{SM}$ in the future to look for information as a result of an extreme weather event. In contrast, only $1.4 \%$ of respondents thought it not at all likely that they would use SM in the future to look for information about an extreme weather event, with $2.3 \%$ reporting it not very likely and $7.9 \%$ reporting to be neutral on this question. Respondents aged 60+ were significantly less likely to believe they would seek information from SM in the future than respondents from LSE backgrounds. There were no other significant differences between respondents' perceptions of whether they were likely to use SM to find out information about an extreme weather event in the future based on the type of vulnerability reported. 
Extremely helpful $\square$ Very helpful $\square$ Somewhat helpful $\square$ Slightly helpful $\square$ Not at all helpful $\square$ Not applicable

\begin{tabular}{|c|c|c|c|c|c|c|}
\hline \multicolumn{7}{|l|}{$100 \%$} \\
\hline \multicolumn{7}{|l|}{$90 \%$} \\
\hline \multicolumn{7}{|l|}{$80 \%$} \\
\hline $60 \%$ & & & & & & \\
\hline $60 \%$ & & & & & & \\
\hline $50 \%$ & & & & & & \\
\hline $40 \%$ & & & & & & \\
\hline $30 \%$ & & & & & & \\
\hline \multirow{2}{*}{\multicolumn{7}{|c|}{$\begin{array}{l}20 \% \\
10 \%\end{array}$}} \\
\hline & & & & & & \\
\hline $0 \%$ & $\begin{array}{l}\text { Emergency } \\
\text { response } \\
\text { organisations } \\
\text { (e.g. police, } \\
\text { fire brigade) }\end{array}$ & \begin{tabular}{|c} 
Government \\
agencies (e.g. \\
Department \\
of Human \\
Services, \\
Bureau of \\
Meteorology)
\end{tabular} & $\begin{array}{l}\text { Non- } \\
\text { government } \\
\text { organisations } \\
\text { (e.g. Red } \\
\text { Cross, } \\
\text { Salvation } \\
\text { Army) }\end{array}$ & $\begin{array}{l}\text { Local } \\
\text { government } \\
\text { (e.g. local } \\
\text { council) }\end{array}$ & \begin{tabular}{|} 
Local \\
community \\
groups (e.g. \\
Grey Nomads, \\
surf clubs)
\end{tabular} & $\begin{array}{c}\text { Local online } \\
\text { groups (e.g. } \\
\text { Twitter feed } \\
\text { or Facebook } \\
\text { page of local } \\
\text { community } \\
\text { group) }\end{array}$ \\
\hline$\square$ Not applicable & 2.3 & 3.7 & 11.6 & 7.9 & 18.1 & 6 \\
\hline Not at all helpful & 1.4 & 2.8 & 4.2 & 7.9 & 7 & 3.7 \\
\hline 口 Slightly helpful & 3.7 & 5.1 & 12.1 & 15.8 & 14.4 & 12.1 \\
\hline Somewhat helpful & 21.9 & 24.2 & 27.9 & 30.7 & 21.9 & 28.8 \\
\hline Very helpful & 30.7 & 36.7 & 26 & 22.3 & 22.3 & 33.5 \\
\hline Extremely helpful & 40 & 27.4 & 18.1 & 15.3 & 16.3 & 15.8 \\
\hline
\end{tabular}

Figure 6. Helpfulness of information on extreme weather events sought via SM from different organisations

When asked what would make them even more likely to use SM in the future to look for information as a result of an extreme weather event, a number of themes emerged. Issues related to characteristics of information were highlighted, including the need for 'official information' that enabled 'quick and live updates' from more 'reliable sources', that is, information that is 'easier to access' and 'more accurate'. Several respondents explained that they would use SM to cross-check information if they had doubts about the usefulness of other information sources, or, if there were no other information sources available. Characteristics of the event were also important. The 'type' of extreme weather event was identified by some respondents as likely to influence whether they would use SM in the future (e.g., size or type of natural hazard). The 'proximity to event or area' was important. For example, one participant stated they would be more likely to use SM, "If I had friends or family who lived in the affected area or if I lived in the affected area and wanted to let loved ones know I was safe." Safety concerns were also mentioned because "if I'm going out or travelling somewhere far. I want to be safe. I want to avoid dangerous area (sic)". Issues relating to friends and family were identified as particularly important for using SM in the future. On the one-hand respondents remarked that "if [the] event is likely to impact myself or extended family members" they could use SM to "... alert my friends and family". On the other hand, respondents revealed that the extent to which friends or family use SM during extreme weather events will influence their own future SM use. For some respondents, certain conditions needed to be met in order for them to use SM more often as a result of an extreme weather event. For instance, "if the extreme weather event hadn't affected Wi-Fi, data or phone signal". Not all respondents were able to provide specific insights into what would make them 
more likely to use SM for gathering information in an extreme weather event providing responses such as, "Nothing", "I don't know", "Not sure", "N/A" as well as "I can't think of anything".

\subsection{Use of information received indirectly via SM}

Almost two-thirds of respondents $(65.6 \%)$ had received information about extreme weather events via SM indirectly (e.g., had a conversation with a friend about a post they'd seen on SM about a flood). An additional $22.3 \%$ were not sure if they had received information about extreme weather events via SM indirectly. The most common type of information received indirectly was about weather conditions or warnings $(75 \%)$, followed by information on damage caused by the event (55\%) and road or traffic conditions (52\%) (Figure 7). Over twothirds $(69.7 \%)$ of all respondents reported that they would either be very likely or quite likely to act on information from SM provided to them indirectly by friends or relatives as a result of an extreme weather event, with only $2.8 \%$ of respondents reporting that they were not at all likely to act based on such information. There was no significant difference in the likelihood of people acting on information sourced indirectly from family or friends' SM in the future based on the different types of vulnerability reported.

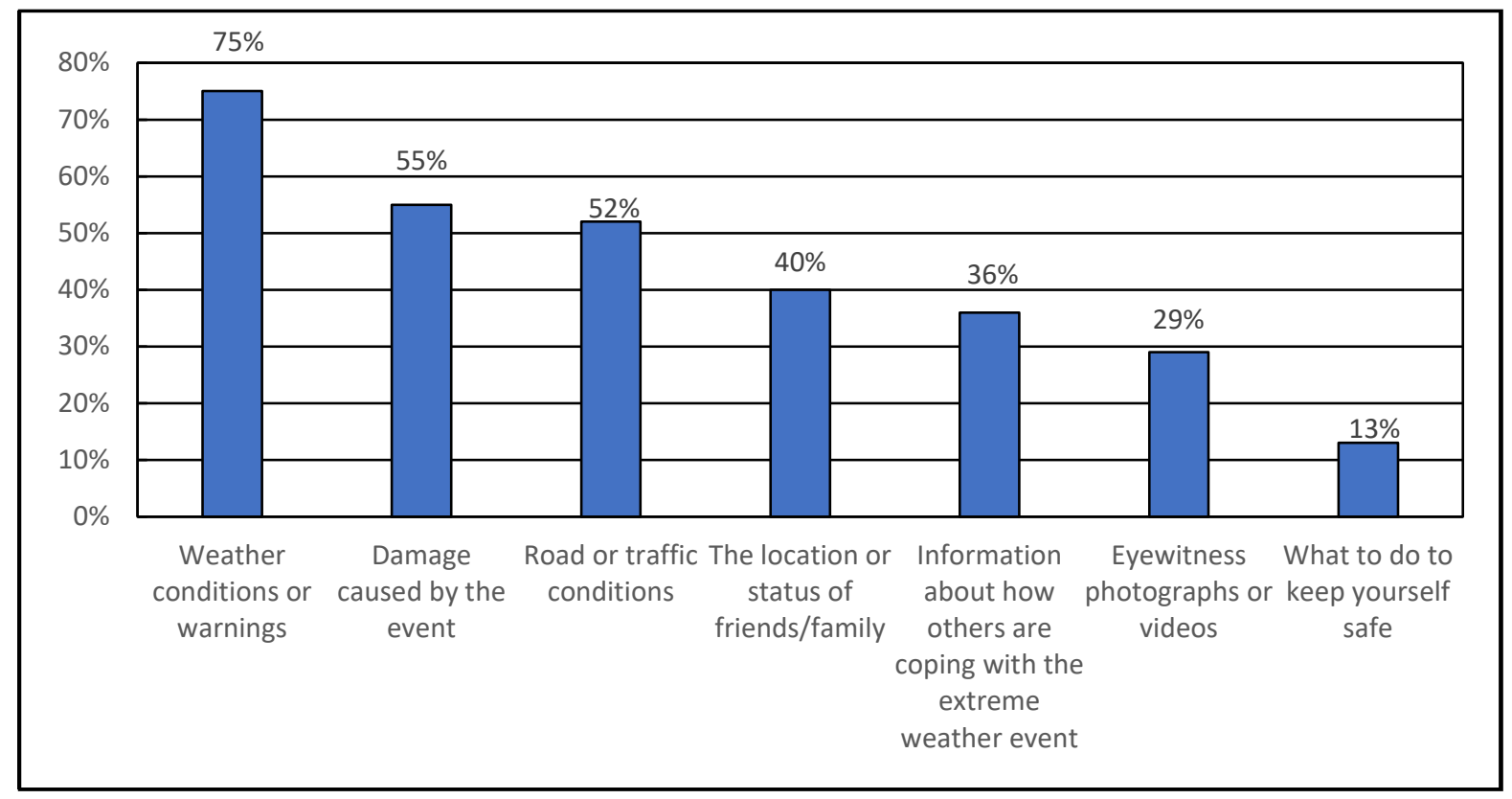

Figure 7. Types of information about extreme weather events received indirectly via SM

When asked what would make respondents even more likely to act upon information about an extreme weather event from SM indirectly through friends or relatives, a number of themes emerged. First, reliability was important, in terms of the perceived trustworthiness of the friend or family member providing them the information, as well as the perceived reliability of the original source that the friend or relative had acquired the information. Some respondents emphasised the importance of being able to verify the information provided by friends or relatives by triangulating this with other information sources. For some, the nature (e.g., severity, extent of threat posed) and proximity of the event (i.e., to themselves, to friends/ relatives) would influence the likelihood of them acting on information received from SM indirectly. Timeliness of the information was also a factor, with 'constant', 'faster', 'current', 'regular' updates being important. A number of respondents noted that "Nothing", "I don't know", "Not sure", as well as "I can't think of anything" would make them more likely to act 
on information received from SM indirectly. Others felt they would need to directly hear or see the news as they lacked confidence in information received indirectly.

\subsection{Sharing information using SM during emergencies}

Almost two-thirds (62.3\%) of respondents have used SM to share information as a result of an extreme weather event. Of those that have shared information, the most common type of information shared was about weather conditions or warnings (75\%), followed by the actions they were taking to stay safe $(57 \%)$, road or traffic conditions $(49 \%)$ and reassurance that they are safe (46\%). Sharing eyewitness videos (16\%) and advice about actions others should take to stay safe $(23 \%)$ were the least common types of information shared (Figure 8$)$. Almost threequarters of respondents $(72.5 \%)$ reported that they would be either quite likely or very likely to use SM in the future to share information regarding an extreme weather event. Only $5.1 \%$ reported that they were not at all likely to do so. There was no significant difference in the likelihood of people using SM in the future to share information based on the different types of vulnerability they reported.

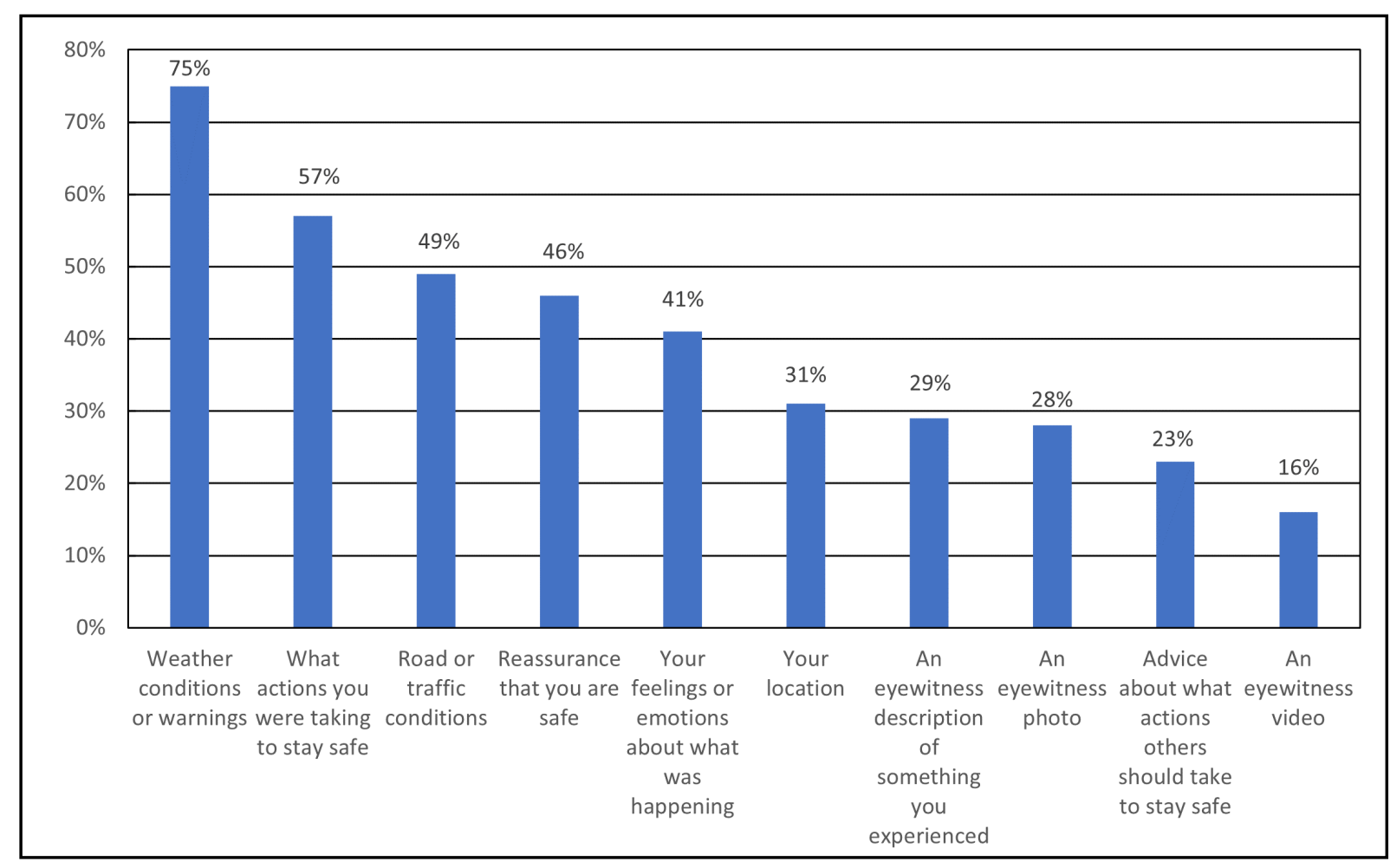

Figure 8. Types of information shared about extreme weather events using SM

We also asked respondents about what would make them even more likely to use SM to share information about an extreme weather event in the future. The most common theme that emerged related to inter-personal relationships such that if respondents felt family or friends were at risk, they would be more likely to share information on SM. The extent to which the respondent thought their posts would help others, and the need to be confident that the information they shared was reliable, also emerged as important. Having photographic evidence to post and the ability to give 'live updates' were reported as influencing factors. The need for easy to access to information from other sources (e.g., emergency services' pages) was considered to influence the likelihood that respondents would share information on SM. Further, proximity of the event, to either themselves or to friends and family, would increase the likelihood that respondents would share information on SM in the future. The severity of 
the event was also a factor. For some respondents, specific technical conditions would need to be met, such as "Social media being more likely to show my posts within the main news feed" or if there were no other communication medium available (e.g., phone service). A number of respondents noted that "Nothing", "I don't know", "Not sure", "N/A" in response to what would make them more likely to share information on SM regarding an extreme weather event. Others noted that "[I] used [SM] a lot when we had our last flood event, and I don't think I could have used it more" and "if I used SM more generally" they would be more likely to post information as a result of an extreme weather event.

\subsection{Preference for SM as an information source compared to alternative information sources}

We asked respondents about why some people prefer to look for information on SM over more traditional media. Many respondents think that people prefer to look for information via SM sites because it is available more quickly $(83.3 \%)$ and is more accessible (81.4\%) (Figure 9). Yet while $40.0 \%$ of respondents either agreed or strongly agreed that people prefer to look for information via SM because it may be more accurate, $41.9 \%$ neither agreed nor disagreed, $15.3 \%$ disagreed, and $2.8 \%$ strongly disagreed that this was the case. Similar proportions of respondents perceived that people prefer to look for information via SM because it is more reliable $(38.2 \%)$, with $40.9 \%$ of respondents neither agreeing nor disagreeing, $17.7 \%$ disagreeing and $3.3 \%$ strongly disagreeing. Almost half the respondents (49.3\%) thought people prefer to look for information via SM because it is richer than information available via more traditional sources, with $11.2 \%$ either disagreeing or strongly disagreeing, and $39.5 \%$ neither agreeing nor disagreeing that this was the case.

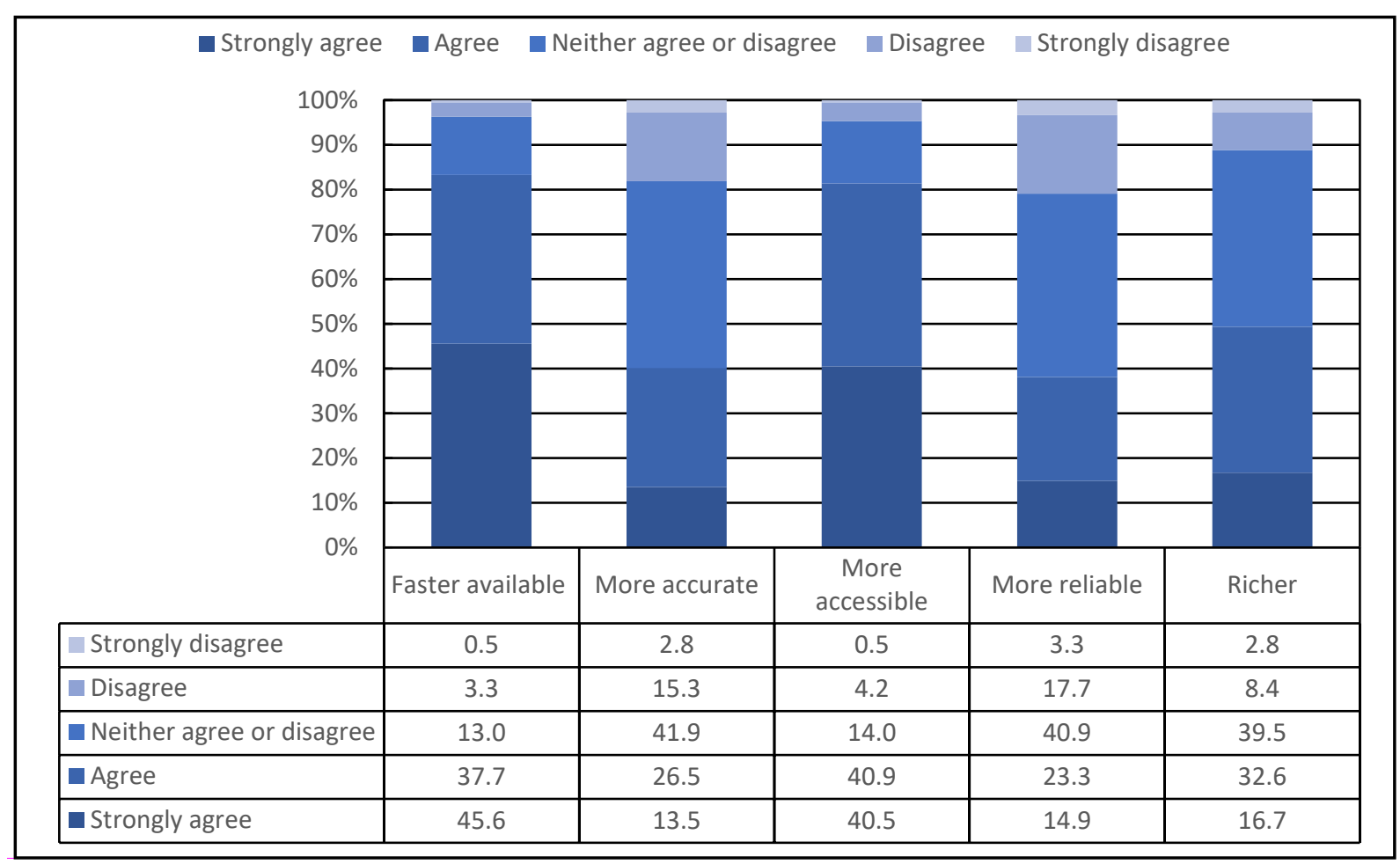

Figure 9. Perceived reasons people prefer to look for information via SM than other sources

Three of the five criteria for why some people prefer to look for information on SM (i.e., information: available faster, more accessible, and more reliable) were significantly different by the type of vulnerability reported. Specifically, LSE and GSI respondents are significantly 
more likely than those aged 60+ to perceive that people prefer to use SM to look for information because the information is available faster. LSE respondents are also significantly more likely than PL respondents to perceive that people prefer to use SM to look for information because the information is available faster. In terms of accessibility, LSE and GSI respondents are significantly more likely than those aged 60+ and those identifying as living with PL to perceive people prefer to look for information on SM than other information sources because it is more accessible. With respect to people preferring to look for information via SM because it is more reliable than other information sources, GSI respondents rated this aspect significantly higher than those aged 60+.

\subsection{Expectations towards emergency services}

The survey included a series of questions exploring how respondents perceived EROs would or should react to them requesting help or information on their SM site. While $75.4 \%$ agreed that emergency services should regularly monitor their SM sites to be able to respond promptly to such a request, $60.5 \%$ of respondents believed emergency services would not know about such a request. Further, $52.5 \%$ of respondents would expect a response within an hour, yet $61.8 \%$ of respondents thought that emergency services are too busy during emergency events to monitor SM (Figure 10).

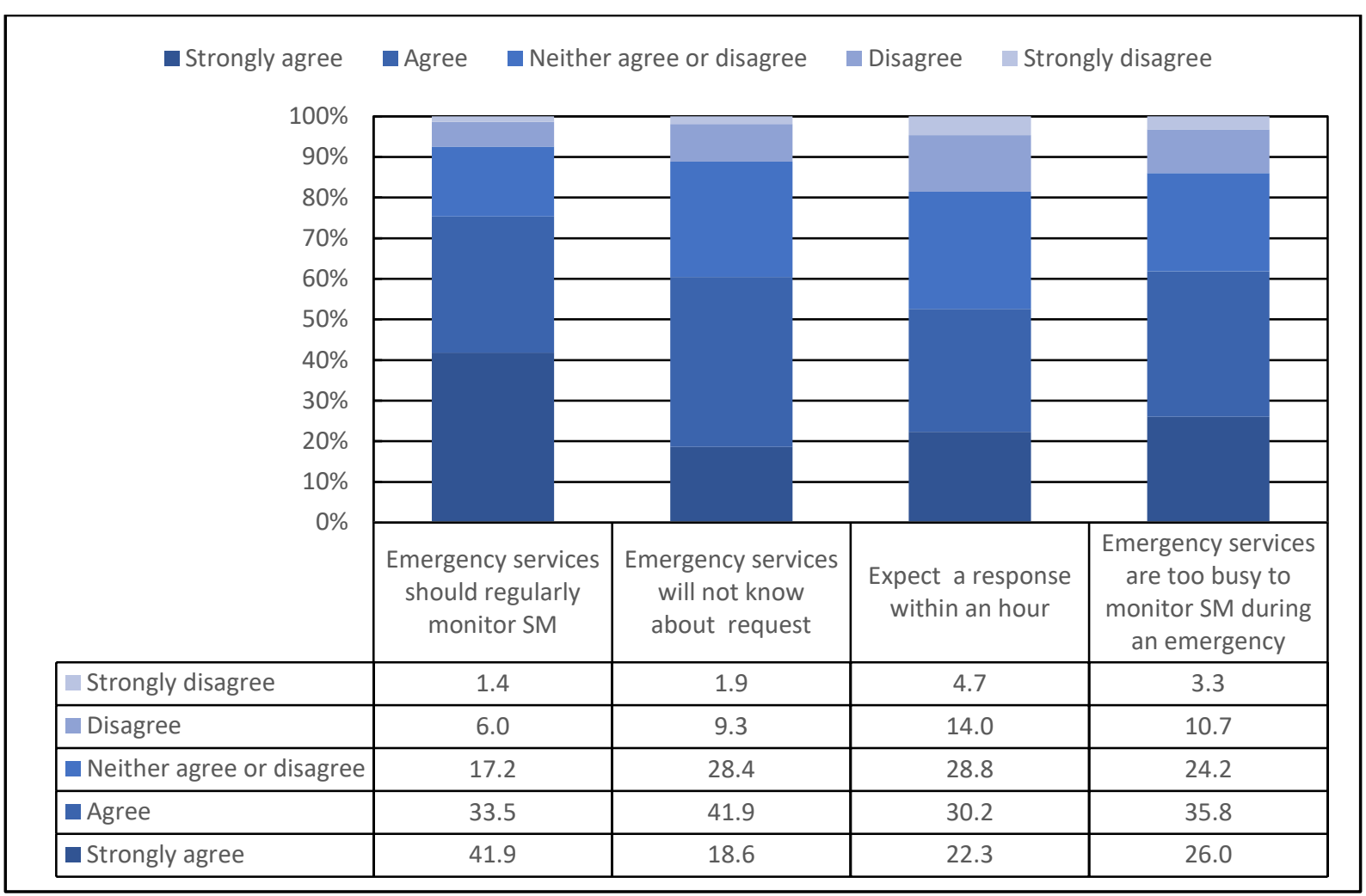

Figure 10. Expectations of emergency services' use of SM

Three of the four criteria capturing participant expectations of emergency services' use of SM (i.e., EROs should regularly monitor SM, expect a response on SM within an hour, and EROs are too busy to monitor SM) were significantly different by the type of vulnerability reported. GSI and LSE respondents had higher expectations of EROs regularly monitoring SM than those aged $60+$. In terms of expecting a response within one hour there were no significant pairwise differences between the vulnerability types. For the third criteria regarding whether 
EROs were too busy to monitor SM, the GSI group agreed that this was the case more so than the LSE respondents.

Over two-thirds of respondents (67.5\%) agreed that the information on SM from emergency services organisations meets their needs (Figure 11). Many respondents $(61.0 \%)$ believed their information needs during extreme weather events are very specific, with almost half $(49.7 \%)$ preferring to use community groups on SM to obtain information because it is tailored towards their needs. Notably, just under half of the respondents (47.4\%) reported that they obtain information specific to their situation offline rather than via SM during extreme weather events.

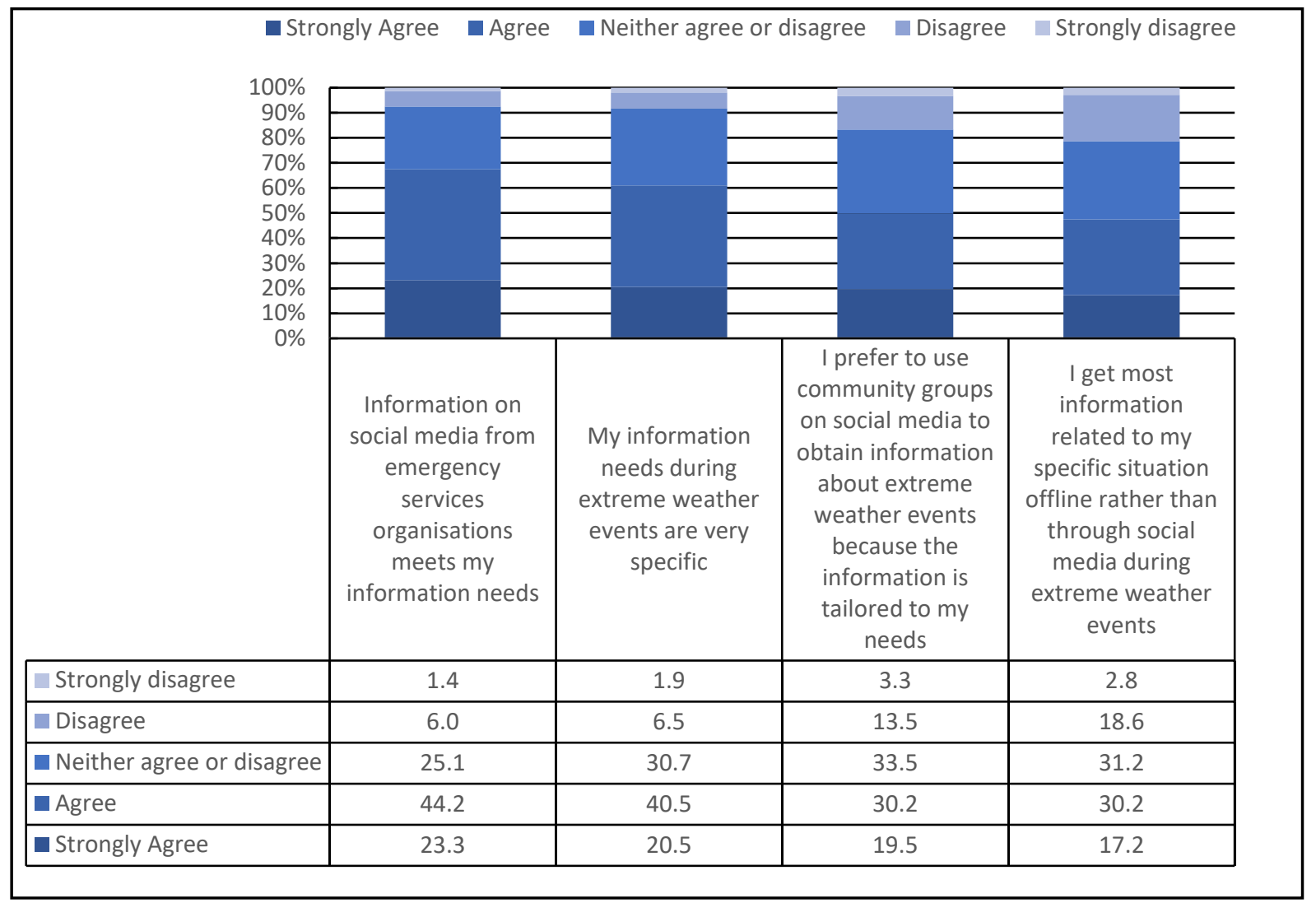

Figure 11. Participant information needs during extreme weather events

For three of the four information needs criteria (i.e., ERO SM information meets my needs, my information needs are very specific, and I obtain most my specific information offline) were significantly different by type of vulnerability. GSI respondents were significantly more likely to believe that information provided by emergency services via SM meets their needs than those aged $60+$ or respondents with PL. This same pattern was seen for the second question regarding the specificity of information needs although GSI respondents also rated their information needs as significantly more specific than LSE respondents. For the third question on preferences for specific information sourced offline, there were no significant pairwise differences.

Respondents were given the opportunity to provide additional comments regarding the use of SM before, during and after an extreme weather event. A number of themes emerged. Several respondents re-emphasised the need for confidence in the information and its source. Some highlighted what they perceived as limitations with SM that could be improved. For example, several respondents highlighted that in extreme weather events phone lines or 
electricity may be down and thus SM may not be available to everyone, while others considered SM inferior to other information sources such as radio, was burdened by advertisements and suffered from having "fake information". Others focused on what they considered benefits of SM, for example, "It's always informative, and there will always be groups started to help those affected. Social media is amazing in pulling people together in a crisis". Several suggested features such as alert systems being built-in to SM and the need for more tailored information. It was noted by one participant that SM applications like Twitter were seen to be more professional and reliable than those like Instagram, yet another emphasised their preference for SM applications that used images. A number offered suggestions around what emergency services organisations could do to improve the usefulness of SM. For example, “Emergency services should have designated people working on social media" and "It is helpful for emergency services to continue to update their social media during an extreme weather event but at the moment they do not share enough information".

\section{Discussion}

Researchers and practitioners have called for research to focus on the specific information needs of vulnerable persons as well as how they use SM (IFRC, 2005, 2013; Pang et al., 2020). In response to this call, we undertook a survey of vulnerable persons in the Australian state of Victoria and focused on understanding their attitudes, needs and future plans to use SM to access and share information during extreme weather events.

\subsection{Challenging prevalent assumptions about vulnerable persons and SM in disasters}

Extant literature has traditionally focused on the ways in which vulnerable persons are more at-risk during disasters, implying a state of weakness, rather than adopting strength-based approaches which emphasise equality, autonomy and empowerment (Ogie \& Pradhan, 2019). The reasons behind this tradition are understandable given that disasters present life or death situations and there is an urgent need to reduce their impact on those who may be less able to fend for themselves. However, recent shifts towards "shared responsibility" in emergency management, whereby the obligations for planning and mitigating against hazards are distributed among different actors (McLennan \& Eburn, 2015) to reduce unrealistic expectations and unsustainable dependences on emergency services personnel (Lukasiewicz, Dovers, \& Eburn, 2017), prompts questions around existing assumptions about vulnerability and vulnerable persons.

In the early stages of our study the importance of informal networks and relationships as a source of information and support for vulnerable persons emerged as important (Section 3.1). We therefore investigated information-related issues surrounding trust, accuracy and usefulness when people receive information from SM indirectly. As highlighted in Section 4.3 almost two-thirds of vulnerable persons $(65.6 \%)$ reported they had received information about extreme weather events indirectly from SM and over two thirds (69.7\%) reported they'd be either very likely or quite likely to act on information provided to them indirectly by friends or family. The relatively high proportion of vulnerable persons receiving and acting on information received from SM indirectly is not unexpected given that posts on SM by emergency organisations tend to target the general public as carers-effectively suggesting they 'check-in' with vulnerable persons (Poblet-Balcell et al., 2018). Poblet-Balcell et al. (2018) 
note that that one reason for this may be because emergency organisations are assuming that vulnerable persons will be less likely or able to use SM to access such information. While this assumption may be accurate for many vulnerable persons, our study indicates that this is certainly not always the case.

Vulnerable persons in our study exhibit a strong desire to use SM during disasters to receive and share information - and in some cases were even more likely to view SM favourably than samples of the general population captured in other studies. This may be because vulnerable people recognise that their level of risk in disasters is higher and consequently, they adopt SM to strengthen their personal networks and improve their access to information. This is consistent with Risk Homeostasis Theory (Wilde, 1998) which proposes that if people subjectively perceive that their level of risk is higher than acceptable, they will compensate for this and modify their behaviour to exercise greater caution. In comparing the results of our study $(n=215)$ to those of Reuter and Spielhofer (2017) $(n=839)$, effect sizes for the difference between two independent proportions (with 95\% confidence interval (CI) upper and lower limits shown in square brackets) (Cumming, 2012), reveal that vulnerable persons were significantly more likely to perceive that they: i) regularly use SM in their private lives $(0.137$ $[0.068,0.198] p<.001)$; ii) use SM in the context of extreme weather events $(0.311[0.239,0.375]$ $p<.001)$; and iii) will use SM in the future to search $(0.303[0.244,0.353] p<.001)$ and share $(0.245[0.174,0.31] p<.001)$ information on extreme weather events. Perceptions of SM compared to traditional media in terms of speed $(0.072[0.01,0.125] p<.024)$, accessibility $(0.274[0.208,0.331] p<.001)$, richness $(0.524[0.459,0.579] p<.001)$, reliability $(0.161[0.092,0.233]$ $p<.001)$ and accuracy $(0.27[0.202,0.34] p<.001)$ were more positive for vulnerable persons. Our study's vulnerable participants were also considerably more aware of Twitter alerts $(20 \%$ vs. $6 \% ; 0.14[0.089,0.201] p<.001)$ and Facebook safety checks $(29.8 \%$ vs. $3 \% ; 0.268[0.209,0.333]$ $p<.001)$ than the sample of the general population captured by Reuter and Spielhofer (2017). Thus, SM offers an increasingly valuable way for governments, EROs, NGOs and community organisations to reach out directly to vulnerable persons and for vulnerable persons to reachout directly to organisations and their communities in ways which complement the wider information ecology of vulnerable persons.

In light of the positive view that vulnerable persons in this study held towards SM in the disaster context, further research into areas where their perceptions do differ from the general population is worthwhile. Such insights could be used to inform tailored SM solutions that maximise outcomes for vulnerable persons. For example, if we compare the expectations vulnerable persons hold of EROs in our study with the sample of the general population captured by Reuter and Spielhofer (2017), vulnerable persons were found to have a significantly higher expectation that emergency services should respond to a post on SM within an hour $(52.5 \%$ compared to $41 \% ; 0.116[0.041,0.189] p<.002)$. This suggests that emergency services might usefully engage with vulnerable persons to better address and manage their expectations. As another example, significantly more respondents in our study $(61.4 \%)$ reported that they would not trust messages on SM apart from those posted by official sources (compared to only $38 \%$ of the general population) $(0.235[0.161,0.305] p<.001)$. While some studies have indicated limited issues with the propagation of rumours via SM during disasters (Hjorth \& Kim, 2011) others have reported concerns from citizens and organisations in relation to inaccurate information (Elbanna et al., 2019; Goolsby, 2010). Future research might investigate how to improve the accuracy and reliability of information to increase 
vulnerable persons' trust in SM during disasters given they seem to have greater concerns surrounding these issues.

In addition to considering how the values, needs and future plans of vulnerable persons to use $\mathrm{SM}$ in disasters when compared to the general population, it is valuable to consider further, how people from different vulnerable groups compare with each other to support more nuanced approaches. We explore these differences next.

\subsection{Comparison of perceptions of SM use in disasters between vulnerable groups}

In addressing the research question our findings suggest that vulnerable persons should not be treated as a homogeneous group but rather, a nuanced approach to engage vulnerable persons using SM is required. Amongst the four types of vulnerable persons examined in our study, those identifying as GSI generally held more positive attitudes towards using SM to access and share information during disasters and were more likely to view their information needs as specific. The views of older persons, on the other hand, were the most divergent. Most of the significant differences between older persons were with those who are of LSE means and/or those who were GSI, whereby older persons typically reported lower levels of awareness and SM use than these two groups. This is not only consistent with research that has shown that older persons are less likely to use ICT and SM than the general population (Barnard, Bradley, Hodgson, \& Lloyd, 2013) but further highlights that this is also the case when older persons are compared to other vulnerable groups. Notably, older persons in our study were less likely to believe the information on SM provided by emergency services meets their needs when compared to GSI respondents. Despite the significant differences identified between older persons and other vulnerable persons in a number of areas, they were also less likely to perceive their information needs during an extreme weather event are very specific. Given the projected growth in the number of older persons and increasing diffusion of ICT there is a pressing need to better understand how technology, including SM, can be better leveraged to support older persons during emergencies (Choudrie, Pheeraphuttranghkoon, \& Davari, 2018). Studies which consider older persons' SM use within their broader information ecology would be of value in order to understand how their use of other tools, and their formal and informal networks, influence their SM use.

The potential of SM to break down barriers and change the lives of people living with disability has been frequently highlighted, nonetheless, accessibility concerns persist (Ellis \& Goggin, 2013). By comparing the responses of people with PLs to other vulnerable groups, our study indicates that in the disaster context accessibility issues remain a concern for people living with disabilities. People with PL were significantly less likely to be positive about the accessibility of information on SM than those of LSE means and GSI persons, and less likely to be convinced that information on SM was available faster than persons of LSE means. People with PLs were less satisfied with the information provided on SM by emergency services and less likely to rate information on SM provided by EROs, community groups and local online groups as helpful compared to GSI persons. Therefore, organisations in the disaster context might usefully consider how they can better customise the information they provide on SM to meet the needs of those living with PLs (Morris et al., 2014).

In our study those of LSE means were less likely to find the information on SM provided by emergency services organisations to be helpful and were less likely to perceive their information needs were specific when compared to GSI respondents. Given education is used 
as a common measure of socio-economic status (Australian Bureau of Statistics, 2011), it would be valuable to identify the extent to which the information provided by emergency services is designed to address the needs of people holding different levels of education. Our study also highlighted that people of LSE means were less likely to think emergency services will be too busy to monitor SM during an extreme weather event when compared to GSI persons. As those of LSE are often characterised by their limited access to resources (Australian Bureau of Statistics, 2011) it would be interesting to examine how this influences their perceptions of the resources available to emergency services organisations compared to other segments of the community.

\section{Contributions, Directions for Future Research and Limitations}

In this section we summarise our contributions research and practice, offer directions for future research and acknowledge the limitations of our study.

\subsection{Contributions to research and practice}

This paper offers several contributions to information systems research. First, although there is a growing body of research on SM and disasters (e.g. Bunker, 2020; Elbanna et al., 2019; Mirbabaie, Bunker, Stieglitz, Marx, \& Ehnis, 2020; Pan \& Zhang, 2020) and on vulnerable persons and disasters (e.g. Abedin \& Babar, 2018; Al-Saggaf \& Simmons, 2015; Kryvasheyeu et al., 2016; Panagiotopoulos et al., 2016; Peary et al., 2012), this is one of only a few studies to address the important topic of SM use by vulnerable persons in disasters specifically. Second, this study challenges prevalent assumptions in extant literature about vulnerable persons and SM in disasters. We provide empirical evidence that indicates vulnerable persons are not passive victims and in fact adopt a shared responsibility (McLennan \& Eburn, 2015) towards disasters through their strong desire to use SM to receive and share information to help themselves and others. We also highlight, by comparing our results to a similar study (Reuter \& Spielhofer, 2017), that vulnerable persons may be more likely to view SM favourably than the general population. Third, this study provides new insights to the literature on the information ecology of vulnerable persons in disasters by illuminating the importance of online and offline information sources, formal and informal networks, and informationrelated issues such as trust, accuracy and usefulness for vulnerable persons using SM in disasters.

This study also offers a number of contributions to practice. First, by demonstrating that vulnerable persons are not a homogeneous group, we are able to illuminate how people with different types of vulnerabilities perceive SM for accessing and sharing information in the context of disasters. The resulting insights can be used by relevant disaster organisations to review the information they provide vulnerable persons during disasters and tailor their SM strategies to better target individuals living with a variety of vulnerabilities. Second, our study highlights that vulnerable persons may have different expectations of EROs than the general population and organisations should usefully engage with vulnerable persons to better address and manage their expectations.

\subsection{Directions for future research}

As one of few studies to specifically examine the use of SM by vulnerable persons during disasters there are several important directions for future research that could further augment 
understanding of the diverse information needs and practices of vulnerable populations during disasters. We summarise these directions in Table 1.

\begin{tabular}{|c|c|}
\hline Theme & Suggested research directions \\
\hline $\begin{array}{l}\text { Nuanced and } \\
\text { specific focus } \\
\text { on the } \\
\text { information } \\
\text { needs and } \\
\text { practices of } \\
\text { vulnerable } \\
\text { persons }\end{array}$ & $\begin{array}{l}\text { - Investigation of the factors which influence the decision of vulnerable persons to } \\
\text { use, or not to use, SM to access and share information during disasters. } \\
\text { - Examination of how vulnerable persons who use SM during disasters differ to } \\
\text { vulnerable persons who do not use SM during disasters. } \\
\text { - Studies of how perceptions of SM use in disasters vary within categories of } \\
\text { vulnerable persons - e.g., 'young old' (60-70), 'old-old' (70-80) and 'oldest-old' } \\
\text { (over 80); disability types (physical, mental) etc. } \\
\text { - Investigation of how different categories of vulnerability interact with each other } \\
\text { and impact perceptions of SM use during disasters. } \\
\text { - Identification of how characteristics such as gender and culture influence categories } \\
\text { of vulnerable persons in their use of SM to access and share information in } \\
\text { disasters. } \\
\text { - Examination of how the social networks of vulnerable persons (e.g., friends, } \\
\text { families, carers) influence their perceptions of SM use in disasters, including studies } \\
\text { which adopt alternative units of analysis (e.g., households). } \\
\text { - Studies which compare the information needs and practices of vulnerable persons } \\
\text { to the general population in the disaster context. }\end{array}$ \\
\hline $\begin{array}{l}\text { Community } \\
\text { initiated SM } \\
\text { groups }\end{array}$ & $\begin{array}{l}\text { - Identification of how community-initiated SM groups can enhance the inclusion of } \\
\text { vulnerable persons across the PPRR phases of disasters. } \\
\text { - Investigation of the needs of vulnerable persons in disasters by analysing } \\
\text { relationship dynamics within community groups on SM. } \\
\text { - Identification of how vulnerable persons contribute to, and benefit from, crowd- } \\
\text { sourcing initiatives in the disaster context. }\end{array}$ \\
\hline $\begin{array}{l}\text { Information- } \\
\text { related issues }\end{array}$ & $\begin{array}{l}\text { - Examination of how information on SM can better target vulnerable persons to } \\
\text { address their needs in the context of disasters. } \\
\text { - Identification of strategies to enhance SM information flow from organisations to } \\
\text { the public; from the public to the public, from the public to organisations and } \\
\text { between organisations to ultimately improve outcomes for vulnerable persons in } \\
\text { disasters. } \\
\text { - Examination of how the accessibility, reliability, timeliness and veracity of } \\
\text { information on SM can be enhanced to deliver better outcomes for vulnerable } \\
\text { persons in disasters. } \\
\text { - Studies on how information received indirectly via SM influences the behaviour of } \\
\text { vulnerable persons in disasters. }\end{array}$ \\
\hline $\begin{array}{l}\text { Organisational } \\
\text { integration of } \\
\mathrm{SM}\end{array}$ & $\begin{array}{l}\text { - Investigation of how the complexities of the organisational landscape in disaster } \\
\text { management can be managed to better leverage SM to address the specific needs of } \\
\text { vulnerable persons. } \\
\text { - Examination of how organisations can effectively integrate SM with traditional } \\
\text { communication channels to better support the needs of vulnerable persons during } \\
\text { disasters. } \\
\text { - Identification of how vulnerable persons' expectations of emergency services } \\
\text { organisations' use of SM can be managed. } \\
\text { - Studies of how different types of organisations can best leverage SM to support } \\
\text { specific groups of vulnerable persons (e.g., the elderly, those living with PLs etc.) }\end{array}$ \\
\hline $\begin{array}{l}\text { Sentiment and } \\
\text { network } \\
\text { analysis }\end{array}$ & $\begin{array}{l}\text { - Investigation of whether sentiment and network analyses can be leveraged to design } \\
\text { disaster management strategies that address the specific needs of vulnerable persons } \\
\text { - Identification of what SM sentiment and network analyses can tell us about the } \\
\text { needs and role of vulnerable persons in disasters is; and identification of how such } \\
\text { analyses can improve outcomes for vulnerable persons across the PPRR phases of } \\
\text { disaster. } \\
\text { - Undertaking sentiment and network analyses to give a voice to vulnerable persons } \\
\text { and democratise participation in disaster management. }\end{array}$ \\
\hline
\end{tabular}

Table 1. Directions for future research 


\subsection{Limitations}

There are several limitations to this research. Most notably, this study only focuses on SM users, it does not account for individuals who do not use SM (an estimated 20.1\% of the population in Australia) (Kemp, 2021) and may be most vulnerable during emergencies. As non-probability sampling was used it cannot be assumed that our results are representative of vulnerable persons in Victoria and beyond. Our study was limited to an investigation of four types of vulnerability. In comparing results between the four vulnerable groups, we did not take into account those who identify as having multiple vulnerabilities. We thus did not investigate the impact of intersectionality and how these can potentially exacerbate vulnerability. Social categorisations such as race and gender can create overlapping and interdependence systems of disadvantage that impact the outcomes of vulnerable persons during emergencies and disaster. Our analysis did not consider these additional social categorisations.

In comparing vulnerable persons' attitudes, needs and future plans towards using SM to access and share information in disasters to the general population (Section 5.2) we utilised the study of Reuter and Spielhofer (2017). While both studies utilised the same survey instrument (albeit modified), they were undertaken at different times (2015 vs. 2018) and with participants from different geographical locations and cultural backgrounds (i.e., Australian vs. European citizens). While arguably there may be as many cultural differences between European countries (Reuter et al., 2019) as there are between Australia and these countries, it is important to be cautious when interpreting the comparative results.

\section{Conclusion}

Although vulnerable persons may suffer disproportionally during disasters, they are not simply passive victims and have been shown to have a strong desire to receive and provide reliable information. Conceptualisations of vulnerability in the literature are moving away from victimhood and viewing vulnerable persons as passive recipients of support, towards recognising those traditionally viewed as vulnerable as having self-awareness and capacities that contribute to social protection and risk reduction (Wisner, 2016). By identifying how vulnerable persons perceive SM use during extreme weather events we have highlighted how they are proactive in protecting themselves and their friends and family. Our findings indicate that SM can empower vulnerable persons in disasters and calls into question assumptions about the lack of technology and SM use by vulnerable persons when compared to the general population. Nonetheless, there is potential for SM to be further leveraged to deliver improved outcomes to those traditionally thought of as more vulnerable. We highlighted a potential mismatch between vulnerable persons' expectations of emergency services in responding to requests for help on SM and the extent to which emergency services will be aware of, and be able to respond to, such requests. Organisations and community groups might consider patterns of usage amongst vulnerable persons more carefully to ensure their SM strategies address their requirements.

\section{References}

Abedin, B., \& Babar, A. (2018). Institutional vs. non-institutional use of social media during emergency response: A case of twitter in 2014 Australian bush fire. Information Systems Frontiers, 20(4), 729-740. https://link.springer.com/article/10.1007/s10796-017-9789-4 
Al-Saggaf, Y., \& Simmons, P. (2015). Social media in Saudi Arabia: Exploring its use during two natural disasters. Technological Forecasting and Social Change, 95, 3-15. https://doi.org/10.1016/j.techfore.2014.08.013

Alexander, D. (2014). Social media in disaster risk reduction and crisis management. Science and Engineering Ethics, 20, 717-733. https://doi.org/10.1007/s11948-013-9502-z

Alwang, J., Siegel, P. B., \& Jorgensen, S. L. (2001). Vulnerability: A view from different disciplines. Retrieved January 13, 2022, from https://documents.worldbank.org/en/publication/ documents-reports/documentdetail/636921468765021121/vulnerability-a-view-fromdifferent- disciplines.

American Red Cross. (2012). Social media in disasters and emergencies. Retrieved July 21, 2021, fromhttp://www.a1881.g.akamai.net/7/1881/26640/v0001/redcross.download.akamai.co $\mathrm{m} /$ 26640/PollData/Social.

Appleby, L. (2013). Connecting the last mile: The role of communications in the Great East Japan Earthquake. Retrieved July 21, 2021, from www.internews.org/sites/default

/files/resources/InternewsEurope_Report_Japan_Connecting\%20the $\% 201$ ast $\% 20 \mathrm{mile} \% 2$ 0Japan_2013.pdf.

Appleby-Arnold, S., Brockdorff, N., Fallou, L., \& Bossu, R. (2019). Truth, trust, and civic duty: Cultural factors in citizens' perceptions of mobile phone apps and social mediain disasters. Journal of Contingencies and Crisis Management, 27(4), 293-305. https://doi.org/10.1111/1468-5973.12282

Australian Bureau of Statistics. (2011). Measures of socioeconomic status: Information paper. Retrieved July 21, 2021, from https://www.ausstats.abs.gov.au/Ausstats/subscriber.nsf/ 0/367D3800605DB064CA2578B60013445C/\$File/1244055001_2011.pdf.

Baker, S., Brown, T., Caleb, N., Marella, M., Morris, K, Nasak, M. ... (2017). Disability inclusion in disaster risk reduction: Experiences of people with disabilitiesin Vanuatu during and after tropical Cyclone Pam and recommendations for humanitarian agencies. CBM - Nossal Institute Partnership for Disability Inclusion Development. Retrieved January 22, 2022, from https://mspgh.unimelb.edu.au/_data/assets/pdf_file/0011/2567576/WEB-DIDRRReport-14112017.pdf

Barnard, Y., Bradley, M. D., Hodgson, F., \& Lloyd, A. D. (2013). Learning to use new technologies by older adults: Perceived difficulties, experimentation behaviour and usability. Computers in Human Behavior, 29(4), 1715-1724. https://doi.org/10.1016/ j.chb.2013.02.006

Bird, D., Ling, M., \& Haynes, K. (2012). Flooding Facebook? The use of social media during the Queensland and Victorian floods. Australian Journal of Emergency Management, 27(1), 27-33.

Buheji, M., da Costa Cunha, K., Beka, G., Mavrić, B., de Souza, Y. L. d. C., da Costa Silva, S. S., ... Yein, T. C. (2020). The extent of COVID-19 pandemic socio-economic impact on global poverty. A global integrative multidisciplinary review. American Journal ofEconomics, 10(4), 213-224. https://doi.org/10.5923/j.economics.20201004.02

Bunker, D. (2020). Who do you trust? The digital destruction of shared situational awareness and the COVID-19 infodemic. International Journal of Information Management, 55, 102201. https://doi.org/10.1016/j.ijinfomgt.2020.102201

Canadian Red Cross. (2012). Social media during emergencies. Retrieved July 21, 2021, from http://www.redcross.ca/cmslib/general/pub_social_media_in_emergencies_survey_oc 012_en.pdf. 
Chan, Y., \& Walmsley, R. P. (1997). Learning and understanding the Kruskal-Wallis one- way analysis-of-variance-by-ranks test for differences among three or more independent groups. Physical Therapy, 77(12), 1755-1761. https://doi.org/10.1093/ptj/77.12.1755

Choudrie, J., Pheeraphuttranghkoon, S., \& Davari, S. (2018). The digital divide and olderadult population adoption, use and diffusion of mobile phones: A quantitative study. Information Systems Frontiers, 23(3), 673-695. https://doi.org/10.1007/s10796-018-9875-2

Cohen, O., Goldberg, A., Lahad, M., \& Aharonson-Daniel, L. (2017). Building resilience: The relationship between information provided by municipal authorities during emergency situations and community resilience. Technological Forecasting and Social Change, 121, 119125. https://doi.org/10.1016/j.techfore.2016.11.008

Cooper, V., Fairbrother, P., Elliott, G., Walker, M., \& Ch'ng, H.-Y. (2020). Shared responsibility and community engagement: Community narratives of bushfire riskinformation in Victoria, Australia. Journal of Rural Studies, 80, 259-272. https://doi.org/10.1016/ j.jrurstud.2020.09.015

Cumming, G. (2012). Understanding the new statistics: Effect sizes, confidence intervals, and metaanalysis. New York: Routledge.

Cutter, S. L. (1996). Vulnerability to environmental hazards. Progress in Human Geography, 20(4), 529-539. https://doi.org/10.1177/030913259602000407

Cutter, S. L., Boruff, B. J., \& Shirley, W. L. (2003). Social vulnerability to environmentalhazards. Social Science Quarterly, 84(2), 242-261. https://doi.org/10.1111/1540-6237.8402002

Deacon, B. (2018). Emergency announcements alone during disasters not reliable in savinglives. Retrieved July 21，2021， from http://www.abc.net.au/news/2018-01-06/emergencyannouncements-alone-during-disasters-not-reliable/9304666

Eakin, H., \& Luers, A. L. (2006). Assessing the vulnerability of social-environmentalsystems. Annual Review of Environment and Resources, 31(1), 365-394. https://doi.org/10.1146/ annurev.energy.30.050504.144352

Elbanna, A., Bunker, D., Levine, L., \& Sleigh, A. (2019). Emergency management in the changing world of social media: Framing the research agenda with the stakeholders through engaged scholarship. International Journal of Information Management, 47, 112120. https://doi.org/10.1016/j.ijinfomgt.2019.01.011

Ellis, K., \& Goggin, G. (2013). Disability and social media. In J. Hunsinger \& T.M. Senft (Eds.), The Social Media Handbook (pp. 126-143): New York: Routledge.

Enang, I., Murray, J., Dougall, N., Wooff, A., Heyman, I., \& Aston, E. (2019). Defining and assessing vulnerability within law enforcement and public health organisations: A scoping review. Health $\mathcal{E}$ Justice, 7(2). https://doi.org/10.1186/s40352-019-0083-z

Feldman, D., Contreras, S., Karlin, B., Basolo, V., Matthew, R., Sanders, B., . . Luke, A. (2016). Communicating flood risk: Looking back and forward at traditional and socialmedia outlets. International Journal of Disaster Risk Reduction, 15, 43-51. https://doi.org/10.1016/j.ijdrr.2015.12.004

Gibson, M. J., \& Hayunga, M. (2006). We can do better: Lessons learned for protecting olderpersons in disasters. Retrieved July 21, 2021, from http://assets.aarp.org/rgcenter/il/better.pdf

Gill, A. Q., Alam, S. L., \& Eustace, J. (2015). Social architecture: An emergency management case study. Australasian Journal of Information Systems, 19, 23-40. https://doi.org/10.3127/ ajis.v19i0.979

Goolsby, R. (2010). Social media as crisis platform: The future of community maps/crisismaps. ACM Transactions on Intelligent Systems and Technology, 1(1), 1-11. https://doi.org/10.1145/1858948.1858955 
Hagar, C. (2013). When disaster strikes, where do you turn? Retrieved July 21, 2021, from https://www.fte.org/teachers/teacher-resources/lesson-plans/disasterslessons/lesson- 3when-disaster-strikes-what-can-government-do/

Hjorth, L., \& Kim, K.-H. Y. (2011). The mourning after: A case study of social media in the 3.11 earthquake disaster in Japan. Television $\mathcal{E}$ New Media, 12(6), 552-559. https://doi.org/10.1177/1527476411418351

Howard, A., Agllias, K., Bevis, M., \& Blakemore, T. (2017). “They'll tell us when to evacuate”: The experiences and expectations of disaster-related communication in vulnerable groups. International Journal of Disaster Risk Reduction, 22, 139-146. https://doi.org/10.1016/j.ijdrr.2017.03.002

Hughes, A. L., \& Tapia, A. H. (2015). Social media in crisis: When professional respondersmeet digital volunteers. Journal of Homeland Security and Emergency Management, 12(3) 679-706. https://doi.org/10.1515/jhsem-2014-0080

IFRC. (2005). World disasters report. Retrieved July 21, 2021, from https://www.ifrc.org/Global/ Publications/disasters/WDR/69001-WDR2005-english- LR.pdf

IFRC. (2013). World disasters report. Retrieved July 21, 2021, from http://www.ifrc.org/PageFiles/134658/WDR\%202013\%20complete.pdf

Karanasios, S., Cooper, V., Hayes, P., \& Adrot, A. (2019, December 15-18). "An iron hand in a velvet glove": The embodiment of the platform logic in the emergency sector. [Paper presentation]. Fortieth International Conference on Information Systems, Munich, Germany. https://aisel.aisnet.org/icis2019/

Karanasios, S., Cooper, V.,Adrot, A., \& Mercieca, D. (2020, January 8-10). Gatekeepers rather than helpless: An exploratory investigation of senior's use of information and communication technology in critical settings. [Paper presentation].53rd Hawaii International Conference on System Sciences (HICSS-53), Honolulu, Hawaii. https://aisel.aisnet.org/hicss-53/

Kaufhold, M. A., Gizikis, A., Reuter, C., Habdank, M., \& Grinko, M. (2019). Avoiding chaotic use of social media before, during, and after emergencies: Design and evaluation of citizens' guidelines. Journal of Contingencies and Crisis Management, 27(3), 198-213. https://doi.org/10.1111/1468-5973.12249

Kaur, H. J., \& Kumar, R. (2015, May 15-16). Sentiment analysis from social media in crisis situations. [Paper presentation]. International Conference on Computing, Communication \& Automation, Noida, India. https://doi.org/10.1109/CCAA.2015.7148383

Kemp, S. (2021). Digital 2021: Australia. Retrieved July 21, 2021, from https://datareportal.com/reports/digital-2021-australia

Kim, J., \& Hastak, M. (2018). Social network analysis: Characteristics of online social networks after a disaster. International Journal of Information Management, 38(1), 86-96. https://doi.org/10.1016/j.ijinfomgt.2017.08.003

Kraska-Miller, M. (2013). Nonparametric statistics for social and behavioral sciences. Boca Raton, Florida: CRC Press.

Kryvasheyeu, Y., Chen, H., Obradovich, N., Moro, E., Van Hentenryck, P., Fowler, J., \& Cebrian, M. (2016). Rapid assessment of disaster damage using social media activity. Science Advances, 2(3). https://doi.org/10.1126/sciadv.1500779

Kulemeka, O. (2014). How people affected by disaster use the Internet: A study of Facebook usage during the 2014 Hazelwood mine fire in Victoria. Australasian Journal of Disaster and Trauma Studies, 18(2), 51-56. 
Lukasiewicz, A., Dovers, S., \& Eburn, M. (2017). Shared responsibility: The who, what and how. Environmental Hazards, 16(4), 291-313. https://doi.org/10.1080/17477891.2017.1298510

Luna, F. (2014). 'Vulnerability', an interesting concept for public health: The case of older persons. Public Health Ethics, 7(2), 180-194. https://doi.org/10.1093/phe/phu012

Luna, F. (2018). Identifying and evaluating layers of vulnerability-a way forward. Developing World Bioethics, 19(2), 86-95. https://doi.org/10.1111/dewb.12206

Luna, S., \& Pennock, M. J. (2018). Social media applications and emergency management: A literature review and research agenda. International Journal of Disaster Risk Reduction,28, 565-577. https://doi.org/10.1016/j.ijdrr.2018.01.006

Mann, H. B., \& Whitney, D. R. (1947). On a test of whether one of two random variables is stochastically larger than the other. The Annals of Mathematical Statistics, 18(1), 50-60. http://www.jstor.org/stable/2236101

Masozera, M., Bailey, M., \& Kerchner, C. (2007). Distribution of impacts of natural disasters across income groups: A case study of New Orleans. Ecological Economics, 63(2-3), 299306. https://doi.org/10.1016/j.ecolecon.2006.06.013

McLennan, B., \& Eburn, M. (2015). Exposing hidden-value trade-offs: Sharing wildfire management responsibility between government and citizens. International Journal of Wildland Fire, 24(2), 162-169. https://doi.org/10.1071/WF12201

Mirbabaie, M., Bunker, D., Stieglitz, S., Marx, J., \& Ehnis, C. (2020). Social media in times of crisis: Learning from Hurricane Harvey for the coronavirus disease 2019 pandemic response. Journal of Information Technology, 35(3), 195-213. https://doi.org/10.1177/0268396220929258

Morris, J. T., Mueller, J. L., \& Jones, M. L. (2014). Use of social media during public emergencies by people with disabilities. Western Journal of Emergency Medicine, 15(5),

567-574. https://doi.org/10.5811/westjem.2014.4.21274

Morrissey, S. A., \& Reser, J. P. (2007). Natural disasters, climate change and mental health considerations for rural Australia. Australian Journal of Rural Health, 15(2), 120-125. https://doi.org/10.1111/j.1440-1584.2007.00865.x

Nakahara, S., \& Ichikawa, M. (2013). Mortality in the 2011 Tsunami in Japan. Journal of Epidemiology, 23(1), 70-73. https://doi.org/10.2188/jea.JE20120114

Ogie, R. I., \& Pradhan, B. (2019). Natural hazards and social vulnerability of place: The strength-based approach applied to Wollongong, Australia. International Journal of Disaster Risk Science, 10(3), 404-420. https://doi.org/10.1007/s13753-019-0224-y

OHCHR. (2015). Thematic study on the rights of persons with disabilities under article 11 of the Convention on the Rights of Persons with Disabilities, on situations of risk and humanitarian emergencies. Retrieved July 21, 2021, from https://www.refworld.org/docid/

56c42c744.html

Onder, G., Rezza, G., \& Brusaferro, S. (2020). Case-fatality rate and characteristics of patients dying in relation to COVID-19 in Italy. JAMA, 323(18), 1775-1776. https://doi.org/10.1001/ jama.2020.4683

Palen, L., Vieweg, S., \& Anderson, K. M. (2011). Supporting "everyday analysts" in safety-and time-critical situations. The Information Society, 27(1), 52-62. https://doi.org/10.1080/ 01972243.2011 .534370

Pan, S. L., \& Zhang, S. (2020). From fighting COVID-19 pandemic to tackling sustainable development goals: An opportunity for responsible information systems research. International Journal of Information Management, 55, 102196. https:/doi.org/10.1016/ 
j.ijinfomgt.2020.102196

Panagiotopoulos, P., Barnett, J., Bigdeli, A. Z., \& Sams, S. (2016). Social media in emergency management: Twitter as a tool for communicating risks to the public. Technological Forecasting and Social Change, 111, 86-96. https://doi.org/10.1016/j.techfore.2016.06.010

Pang, N., Karanasios, S., \& Anwar, M. (2020). Exploring the information worlds of older persons during disasters. Journal of the Association for Information Science and Technology, 71(6), 619-631. https://doi.org/10.1002/asi.24294

Peary, B. D., Shaw, R., \& Takeuchi, Y. (2012). Utilization of social media in the east Japan earthquake and tsunami and its effectiveness. Journal of Natural Disaster Science, 34(1),318. https://doi.org/10.2328/jnds.34.3.

Poblet-Balcell, M., Cooper, V., \& Karanasios, S. (2018, November 5-7). Look after your neighbours: Social media and vulnerable groups during extreme weather events. [Paper presentation]. Information Systems for Crisis Response and Management (ISCRAM) Asia-Pacific, Wellington, New Zealand. https://www.confer.co.nz/iscramasiapacific2018/conferenceproceedings-online/

Qiu, J., Xu, L., Wang, J., \& Gu, W. (2020). Mutual influences between message volume and emotion intensity on emerging infectious diseases: An investigation with microblogdata. Information \& Management, 57(4), 103217. https://doi.org/10.1016/j.im.2019.103217

Qu, Y., Wu, P. F., \& Wang, X. (2009, January 5-8). Online community response to major disaster: A study ofTianya forum in the 2008 Sichuan earthquake. [Paper presentation]. 42nd Hawaii Conference on Systems Sciences (HICSS-42), Waikoloa, Hawaii. https://www.computer.org/csdl/proceedings/hicss/2009/12OmNwD1pUh

Reuter, C., Kaufhold, M.-A., Schmid, S., Spielhofer, T., \& Hahne, A. S. (2019). The impact of risk cultures: Citizens' perception of social media use in emergencies across Europe. Technological Forecasting and Social Change, 148. https://doi.org/10.1016/j.techfore.2019. 119724

Reuter, C., Kaufhold, M.-A., Spahr, F., Spielhofer, T., \& Hahne, A. S. (2020). Emergency service staff and social media- a comparative empirical study of the attitude by emergency services staff in Europe in 2014 and 2017. International Journal of DisasterRisk Reduction, 46, 101516. https://doi.org/10.1016/j.ijdrr.2020.101516

Reuter, C., Marx, A., \& Pipek, V. (2012). Crisis management 2.0: Towards a systematization of social software use in crisis situations. International Journal of Information Systems forCrisis Response and Management (IJISCRAM), 4(1), 1-16. https://doi.org/10.4018/jiscrm. 2012010101

Reuter, C., \& Spielhofer, T. (2017). Towards social resilience: A quantitative and qualitative survey on citizens' perception of social media in emergencies in Europe. Technological Forecasting and Social Change, 121, 168-180. https://doi.org/10.1016/j.techfore.2016.07.038

Schmidt, A., Wolbers, J., Ferguson, J., \& Boersma, K. (2017). Are you Ready2Help? Conceptualizing the management of online and onsite volunteer convergence. Journal of Contingencies and Crisis Management, 1-12. https://doi.org/10.1111/1468-5973.12200

Schmidt, S., \& Galea, E. (2013). Recommendations for different types of end-users. In S. Schmidt \& E. Galea (Eds.), Human behaviour in emergencies and disasters: A cross- cultural investigation (pp. 11-20). Berlin: Pabst Science Publishers.

Smoyer Tomic, K. E. (2003). Heat wave. JAMA, 289(12), 1573-1574.https://doi.org/10.1001/ jama.289.12.1573 
Stephenson, D. B., Diaz, H., \& Murnane, R. (2008). Definition, diagnosis, and origin ofextreme weather and climate events. Climate Extremes and Society, 340, 11-23. https://doi.org/10.1017/CBO9780511535840.004

Teo, M., Goonetilleke, A., Ahankoob, A., Deilami, K., \& Lawie, M. (2018). Disaster awareness and information seeking behaviour among residents from low socio-economic backgrounds. International Journal of Disaster Risk Reduction, 31, 1121-1131. https://doi.org/10.1016/j.ijdrr.2018.09.008

Thomas, D. R. (2006). A general inductive approach for analyzing qualitative evaluationdata. American Journal of Evaluation, 27(2), 237-246. https://doi.org/10.1177/1098214005283748

UNISDR. (2016). Report of the open-ended intergovernmental expert working group on indicatorsand terminology relating to disaster risk reduction. Retrieved July 21, 2021 from https://www.preventionweb.net/files/50683_oiewgreportenglish.pdf

Wilcoxon, F. (1945). Individual comparisons by ranking methods. Biometrics Bulletin, 1(6),8083. https://doi.org/10.2307/3001968

Wilde, G. J. (1998). Risk homeostasis theory: An overview. Injury prevention, 4(2), 89-91. http://dx.doi.org/10.1136/ip.4.2.89

Wisner, B. (2004). Assessment of capability and vulnerability. In G Bankoff \& G Frerks (Eds.), Mapping Vulnerability: Disasters, Development and People (pp. 183-193). Routledge.

Wisner, B. (2016). Vulnerability as concept, model, metric, and tool. In Oxford Research Encyclopedia of Natural Hazard Science. Retrieved January 13, 2022, from https://oxfordre.com/naturalhazardscience/view/10.1093/acrefore/9780199389407.001.00 01/acrefore-9780199389407-e-25.

Wolbers, J. J., Boersma, F. K., Ferguson, J. E., Mulder, F., \& Groenewegen, P. (2016). Two faces of disaster response: Transcending the dichotomy of control and collaborationduring the Nepal earthquake relief operation. International Journal of Mass Emergencies and Disasters, 34(4), 419. https://arro.anglia.ac.uk/id/eprint/705792/

Zebardast, E. (2013). Constructing a social vulnerability index to earthquake hazards using a hybrid factor analysis and analytic network process (F'ANP) model. Journal of the International Society for the Prevention and Mitigation of Natural Hazards, 65(3), 1331- 1359. https://doi.org/10.1007/s11069-012-0412-1

\section{Appendix One - Survey instrument}

1. We care about the quality of our survey data and hope to receive the most accurate measures of your opinions, so it is important to us that you thoughtfully provide your best answer to each question in the survey.

Do you commit to providing your thoughtful and honest answers to the questions in this survey?

\begin{tabular}{|l|}
\hline I will provide my best answers \\
\hline I will not provide my best answers \\
\hline I can't promise either way \\
\hline
\end{tabular}

2. Have you ever used social media such as Facebook, Twitter, Instagram, etc. to find or share information as a result of an extreme weather event such as a flood, storm, fire or heatwave?

\begin{tabular}{|l|}
\hline Yes \\
\hline No \\
\hline
\end{tabular}

3. Please indicate which of the following (if any) you identify as being/having 
Over 60 years of age

Geographically or socially isolated (e.g. live in a remote community, or live alone in an urban area)

Suffer from physical limitations (in terms of a physical functioning, mobility, dexterity etc.)

Low socio-economic means

None of the above

4. In which Australian state or territory do you currently live?

\begin{tabular}{|l|}
\hline New South Wales \\
\hline Queensland \\
\hline South Australia \\
\hline Tasmania \\
\hline Victoria \\
\hline Western Australia \\
\hline Australian Capital Territory \\
\hline Northern Territory \\
\hline I do not currently live in Australia \\
\hline
\end{tabular}

5. What is your age?

\begin{tabular}{|l|}
\hline $18-21$ \\
\hline $22-29$ \\
\hline $30-39$ \\
\hline $40-49$ \\
\hline $50-59$ \\
\hline $60-69$ \\
\hline 70 or older \\
\hline
\end{tabular}

6. What is your gender:

\begin{tabular}{|l|}
\hline Male \\
\hline Female \\
\hline Other \\
\hline
\end{tabular}

7. What is your highest level of education?

\begin{tabular}{|l|}
\hline High school \\
\hline Diploma \\
\hline Bachelor degree \\
\hline Master degree \\
\hline Doctoral degree \\
\hline Other (please specify): \\
\hline
\end{tabular}

\section{Please specify your nationality}

9. Are you from a non-English speaking background?

\begin{tabular}{|l|}
\hline Yes \\
\hline No \\
\hline
\end{tabular}

10. Do you have any children under the age of 18 ?

\begin{tabular}{|l|}
\hline Yes \\
\hline No \\
\hline
\end{tabular}

11 What type of household best describes your living situation? 


\begin{tabular}{|l|}
\hline Lone-person household \\
\hline Family household with children \\
\hline Family household without children \\
\hline Group-household (two or more unrelated adults) \\
\hline Other (please specify) \\
\hline
\end{tabular}

\section{What is your current employment status?}

\begin{tabular}{|l|}
\hline Full-time \\
\hline Part-time \\
\hline Casual \\
\hline Fixed-term \\
\hline Shift worker \\
\hline Self-employed \\
\hline Pensioner \\
\hline Retired \\
\hline Homemaker \\
\hline Unemployed \\
\hline Other (please specify) \\
\hline
\end{tabular}

13. To what extent do you currently use the following type of technology?

\begin{tabular}{|l|l|l|l|l|}
\hline Type of Technology & Often & Sometimes & Seldom & Never \\
\hline Desktop computer & & & & \\
\hline Laptop & & & & \\
\hline Tablet & & & & \\
\hline Regular mobile phone (not a smart phone) & & & & \\
\hline Smartphone & & & & \\
\hline Other (please specify) & & & & \\
\hline
\end{tabular}

14. To what extent do you currently use the following types of social media to share or look at information?

\begin{tabular}{|l|l|l|l|l|}
\hline Type of Social Media & Often & Sometimes & Seldom & Never \\
\hline Facebook & & & & \\
\hline Twitter & & & & \\
\hline Instagram & & & & \\
\hline Blogs & & & & \\
\hline YouTube & & & & \\
\hline Others (please specify) & & & & \\
\hline
\end{tabular}

15. Typically how much time do you actively spend on social media?

\begin{tabular}{|c|c|c|c|c|c|}
\hline & 1 & 2 & 3 & 4 & \begin{tabular}{|lr}
5 & or \\
hours &
\end{tabular} \\
\hline Per day & \multicolumn{5}{|c|}{------------ | --------------------------- } \\
\hline Per day during an extreme weather event & \multicolumn{5}{|c|}{ |-----------------| |-------------------- } \\
\hline
\end{tabular}

16. Please indicate how strongly you agree or disagree with the following statements

\begin{tabular}{|l|l|l|l|l|l|}
\hline Item & $\begin{array}{l}\text { Strongly } \\
\text { agree }\end{array}$ & Agree & $\begin{array}{l}\text { Neither } \\
\text { agree or } \\
\text { disagree }\end{array}$ & Disagree & $\begin{array}{l}\text { Strongly } \\
\text { disagree }\end{array}$ \\
\hline In my private life, I use social media very often & & & & & \\
\hline I regularly post messages on social media such & & & & & \\
\hline
\end{tabular}




\begin{tabular}{|l|l|l|l|l|l|}
\hline as Twitter, Facebook or Instagram & & & & & \\
\hline $\begin{array}{l}\text { Most of my friends use social media to keep in } \\
\text { touch }\end{array}$ & & & & & \\
\hline $\begin{array}{l}\text { It is important for emergency services to use } \\
\text { social media to keep in touch with the public } \\
\text { during emergencies }\end{array}$ & & & & & \\
\hline $\begin{array}{l}\text { I would not trust a message posted on social } \\
\text { media during an emergency unless it came } \\
\text { from an official source such as the police or fire } \\
\text { service }\end{array}$ & & & & & \\
\hline $\begin{array}{l}\text { Emergency services should not trust } \\
\text { information on social media }\end{array}$ & & & & & \\
\hline
\end{tabular}

17. Which of the following communication channels have you ever used to get information about an extreme weather event such as a flood, storm, fire or heatwave?

\begin{tabular}{|l|}
\hline TV \\
\hline Local radio station \\
\hline Online news \\
\hline Mobile apps \\
\hline Social media (Facebook, Twitter, Instagram, etc.) \\
\hline Text message alerts \\
\hline Online sites for extreme weather agencies or emergency services \\
\hline None of the these \\
\hline Other (please specify) \\
\hline
\end{tabular}

18. When using social media such as Facebook, Twitter, Instagram, etc. to find out information as a result of an extreme weather event such as a flood, storm, fire or heatwave, what kind of information have you looked for?

\begin{tabular}{|l|}
\hline Weather conditions or warnings \\
\hline Road or traffic conditions \\
\hline Damage caused by the event \\
\hline The location or status of friends/family \\
\hline Information about how others are coping with the extreme weather event \\
\hline Eyewitness photographs or videos \\
\hline What to do to keep yourself safe \\
\hline Other (please specify) \\
\hline
\end{tabular}

19. How helpful was the information you sought using social media about an extreme weather event from each of the following organisations?

\begin{tabular}{|l|l|l|l|l|l|l|}
\hline Organisation type & $\begin{array}{l}\text { Extremely } \\
\text { helpful }\end{array}$ & $\begin{array}{l}\text { Very } \\
\text { helpful } \\
\text { helpful }\end{array}$ & $\begin{array}{l}\text { Somewhat } \\
\text { helpful }\end{array}$ & $\begin{array}{l}\text { Slightly at } \\
\text { helpful }\end{array}$ & $\begin{array}{l}\text { Not } \\
\text { applicable }\end{array}$ \\
\hline $\begin{array}{l}\text { Emergency response } \\
\text { organisations (e.g. police, } \\
\text { fire brigade) }\end{array}$ & & & & & & \\
\hline $\begin{array}{l}\text { Government agencies } \\
\text { (e.g. Department of } \\
\text { Human Services, Bureau } \\
\text { of Meteorology) }\end{array}$ & & & & & & \\
\hline $\begin{array}{l}\text { Non-government } \\
\text { organisations (e.g. Red } \\
\text { Cross, Salvation Army) }\end{array}$ & & & & & & \\
\hline $\begin{array}{l}\text { Local government (e.g. } \\
\text { local council) }\end{array}$ & & & & & & \\
\hline
\end{tabular}




\begin{tabular}{|l|l|l|l|l|l|l|}
\hline $\begin{array}{l}\text { Local community groups } \\
\text { (e.g. Grey Nomads, surf } \\
\text { clubs) }\end{array}$ & & & & & & \\
\hline $\begin{array}{l}\text { Local online groups (e.g. } \\
\text { Twitter feed or Facebook } \\
\text { page of local community } \\
\text { group) }\end{array}$ & & & & & & \\
\hline Other (please specify) & & & & & & \\
\hline
\end{tabular}

20. How likely are you to use social media in the future to look for information as a result of an extreme weather event such as a flood, storm, fire or heatwave?

\begin{tabular}{|l|}
\hline Very likely \\
\hline Quite likely \\
\hline Neutral \\
\hline Not very likely \\
\hline Not at all likely \\
\hline
\end{tabular}

21. What would make you (even) more likely to use social media to look for information as a result of an extreme weather event such as a flood, storm, fire or heatwave in the future?

22. Have you ever received information about an extreme weather event from social media indirectly, i.e., passed on to you by someone that found the information via social media - (e.g. had a conversation with a friend about a post they saw on social media in relation to a flood)?

\begin{tabular}{|l|}
\hline Yes \\
\hline No \\
\hline Don't know/not sure \\
\hline
\end{tabular}

23. What information about an extreme weather event did you receive indirectly from social media?

\begin{tabular}{|l|}
\hline Weather conditions or warnings \\
\hline Road or traffic conditions \\
\hline Damage caused by the event \\
\hline The location or status of friends/family \\
\hline Information about how others are coping with the extreme weather event \\
\hline Eyewitness photographs or videos \\
\hline What to do to keep yourself safe \\
\hline Other (please specify) \\
\hline
\end{tabular}

24. How likely are you to act upon information from social media provided to you indirectly by friends or relatives as a result of an extreme weather event such as a flood, storm, fire or heatwave?

\begin{tabular}{|l|}
\hline Very likely \\
\hline Quite likely \\
\hline Neutral \\
\hline Not very likely \\
\hline Not at all likely \\
\hline
\end{tabular}

25. What would make you (even) more likely to act upon information from social media provided to you indirectly by friends or relatives in the future as a result of an extreme weather event such as a flood, storm, fire or heatwave?

26. Have you ever used social media to share information as a result of an extreme weather event such as a flood, storm, fire or heatwave (e.g. posted a status update about an accident, tagged a friend in a news story about a fire, uploaded a picture of a flood)? 


\begin{tabular}{|l|}
\hline Yes \\
\hline No \\
\hline Don't know/not sure \\
\hline
\end{tabular}

27. What kind of information have you shared using social media as a result of an extreme weather event such as a flood, storm, fire or heatwave?

\begin{tabular}{|l|}
\hline Weather conditions or warnings \\
\hline Road or traffic conditions \\
\hline Reassurance that you are safe \\
\hline Your feelings or emotions about what was happening \\
\hline Your location \\
\hline What actions you were taking to stay safe \\
\hline An eyewitness description of something you experienced \\
\hline Advice about what actions others should take to stay safe \\
\hline An eyewitness photo \\
\hline An eyewitness video \\
\hline Other (please specify) \\
\hline
\end{tabular}

28. How likely are you to use social media in the future to share information with others during or after an extreme weather event such as a flood, storm, fire or heatwave?

\begin{tabular}{|l|}
\hline Very likely \\
\hline Quite likely \\
\hline Neutral \\
\hline Not very likely \\
\hline Not at all likely \\
\hline
\end{tabular}

29. What would make you (even) more likely to use social media to share information as a result of an extreme weather event such as a flood, storm, fire or heatwave?

30. Some people prefer now to look for information via social media rather than via $\mathrm{TV}$, radio or traditional websites for the following reasons?

\begin{tabular}{|l|l|l|l|l|l|}
\hline & $\begin{array}{l}\text { Strongly } \\
\text { agree }\end{array}$ & Agree & $\begin{array}{l}\text { Neither agree } \\
\text { or disagree }\end{array}$ & Disagree & $\begin{array}{l}\text { Strongly } \\
\text { disagree }\end{array}$ \\
\hline $\begin{array}{l}\text { The information via social media is } \\
\text { available faster }\end{array}$ & & & & \\
\hline $\begin{array}{l}\text { The information via social media is } \\
\text { more accurate }\end{array}$ & & & & & \\
\hline $\begin{array}{l}\text { The information via social media is } \\
\text { more accessible }\end{array}$ & & & & & \\
\hline $\begin{array}{l}\text { The information via social media is } \\
\text { more reliable }\end{array}$ & & & & & \\
\hline $\begin{array}{l}\text { The information via social media is } \\
\text { richer }\end{array}$ & & & & & \\
\hline
\end{tabular}

31. Imagine that you posted an urgent request for help or information on a social media site of a local emergency response organisation, such as your local police, coast guard, fire or medical emergency service. To what extent do you agree with the following statements?

\begin{tabular}{|l|l|l|l|l|l|}
\hline & $\begin{array}{l}\text { Strongly } \\
\text { agree }\end{array}$ & Agree & $\begin{array}{l}\text { Neither } \\
\text { agree or } \\
\text { disagree }\end{array}$ & Disagree & $\begin{array}{l}\text { Strongly } \\
\text { disagree }\end{array}$ \\
\hline $\begin{array}{l}\text { Emergency services should regularly } \\
\text { monitor their social media so they can } \\
\text { promptly respond to such a request. }\end{array}$ & & & & & \\
\hline
\end{tabular}




\begin{tabular}{|l|l|l|l|l|l|}
\hline $\begin{array}{l}\text { It is very likely that the emergency } \\
\text { service will not know about this request. }\end{array}$ & & & & & \\
\hline $\begin{array}{l}\text { I would expect to get a response from } \\
\text { them within an hour. }\end{array}$ & & & & & \\
\hline $\begin{array}{l}\text { Emergency services are too busy to } \\
\text { monitor social media during an } \\
\text { emergency. }\end{array}$ & & & & & \\
\hline
\end{tabular}

32. To what extent are you aware or have you heard of the following services provided via social media?

\begin{tabular}{|l|l|l|l|l|l|}
\hline & $\begin{array}{l}\text { Very } \\
\text { aware }\end{array}$ & $\begin{array}{l}\text { Moderately } \\
\text { aware }\end{array}$ & $\begin{array}{l}\text { Somewhat } \\
\text { aware }\end{array}$ & $\begin{array}{l}\text { Slightly } \\
\text { aware }\end{array}$ & $\begin{array}{l}\text { Not at all } \\
\text { aware }\end{array}$ \\
\hline $\begin{array}{l}\text { Twitter alerts - used by key } \\
\text { organisations to send alerts during } \\
\text { emergencies. }\end{array}$ & & & & & \\
\hline $\begin{array}{l}\text { Facebook safety checks - allows you } \\
\text { during an emergency to let friends and } \\
\text { family know you and friends are safe. }\end{array}$ & & & & & \\
\hline
\end{tabular}

33. To what extent do you agree with the following statements?

\begin{tabular}{|l|l|l|l|l|l|}
\hline & $\begin{array}{l}\text { Strongly } \\
\text { agree }\end{array}$ & Agree & $\begin{array}{l}\text { Neither } \\
\text { agree or } \\
\text { disagree }\end{array}$ & Disagree & $\begin{array}{l}\text { Strongly } \\
\text { disagree }\end{array}$ \\
\hline $\begin{array}{l}\text { Information on social media from } \\
\text { emergency services organisations meets } \\
\text { my information needs }\end{array}$ & & & & \\
\hline $\begin{array}{l}\text { My information needs during extreme } \\
\text { weather events are very specific }\end{array}$ & & & & & \\
\hline $\begin{array}{l}\text { I prefer to use community groups on } \\
\text { social media to obtain information } \\
\text { about extreme weather events because } \\
\text { the information is tailored to my needs }\end{array}$ & & & & & \\
\hline $\begin{array}{l}\text { I get most information related to my } \\
\text { specific situation offline rather than } \\
\text { through social media during extreme } \\
\text { weather events }\end{array}$ & & & & & \\
\hline
\end{tabular}

34. Is there anything else you want to mention with regard to the use of social media before, during or after an extreme weather event such as a flood, storm, fire or heatwave? 


\section{Appendix Two - Summary Tables for Quantitative Analysis}

\begin{tabular}{|c|c|c|c|c|c|}
\hline $\begin{array}{l}\text { Independent } \\
\text { variable }\end{array}$ & $\begin{array}{l}\text { Dependent } \\
\text { variable }\end{array}$ & $\begin{array}{l}\text { Kruskal- } \\
\text { Wallis } \mathrm{H} \text { test } \\
\chi^{2}, d f \text {, and } n\end{array}$ & $p$-value & $\begin{array}{l}\text { Mean rank for each } \\
\text { vulnerability type }\end{array}$ & $\begin{array}{l}\text { Post hoc paired Mann- } \\
\text { Whitney test }(p<.05)^{*}\end{array}$ \\
\hline \multirow[t]{4}{*}{$\begin{array}{l}\text { Vulnerability } \\
\text { type (i.e., Aged } \\
60+, \text { LSE, PL or } \\
\text { GSI) }\end{array}$} & Twitter & $8.206,3,167$ & .042 & $\begin{array}{l}\text { Age } 60+=64.38 \\
\text { LSE }=84.90 \\
\text { PL }=83.40 \\
\text { GSI }=94.06\end{array}$ & $\begin{array}{l}\text { Age 60+ use Twitter } \\
\text { significantly less than: } \\
\text { - GSI }\end{array}$ \\
\hline & Instagram & $20.726,3,167$ & $<.001$ & $\begin{array}{l}\text { Age } 60+=53.87 \\
\text { LSE }=86.35 \\
\text { PL }=78.12 \\
\text { GSI }=100.83\end{array}$ & $\begin{array}{l}\text { Age } 60+\text { use Instagram } \\
\text { significantly less than: } \\
\text { - LSE } \\
\text { - GSI } \\
\end{array}$ \\
\hline & YouTube & $14.470,3,167$ & .002 & $\begin{array}{l}\text { Age } 60+=59.75 \\
\mathrm{LSE}=93.29 \\
\mathrm{PL}=74.19 \\
\mathrm{GSI}=92.41\end{array}$ & $\begin{array}{l}\text { Age 60+ use YouTube } \\
\text { significantly less than: } \\
\text { - LSE } \\
\text { - GSI }\end{array}$ \\
\hline & Chat tools & $10.025,3,167$ & .018 & $\begin{array}{l}\text { Age } 60+=60.37 \\
\text { LSE }=86.81 \\
\text { PL }=88.54 \\
\text { GSI }=91.88\end{array}$ & $\begin{array}{l}\text { Age } 60+\text { use chat tools } \\
\text { significantly less than: } \\
\text { - GSI }\end{array}$ \\
\hline
\end{tabular}

Table A1. Kruskal-Wallis $H$ test and post hoc paired Mann-Whitney test analyses of vulnerability type by SM application use

Note: (i) *Significance values have been adjusted by the Bonferroni correction for multiple tests

\begin{tabular}{|c|c|c|c|c|c|}
\hline $\begin{array}{l}\text { Independent } \\
\text { variable }\end{array}$ & $\begin{array}{l}\text { Dependent } \\
\text { variable }\end{array}$ & $\begin{array}{l}\text { Kruskal- } \\
\text { Wallis } \mathrm{H} \\
\text { test } \chi^{2}, d f \text {, } \\
\text { and } n\end{array}$ & $p$-value & $\begin{array}{l}\text { Mean rank for each } \\
\text { vulnerability type }\end{array}$ & $\begin{array}{l}\text { Post hoc paired Mann- } \\
\text { Whitney test }(p<.05)^{*}\end{array}$ \\
\hline \multirow[t]{4}{*}{$\begin{array}{l}\text { Vulnerability } \\
\text { type (i.e., } \\
\text { Aged } 60+, \\
\text { LSE, PL or } \\
\text { GSI) }\end{array}$} & $\begin{array}{l}\text { In my } \\
\text { private life, I } \\
\text { use SM very } \\
\text { often }\end{array}$ & $\begin{array}{l}18.143,3, \\
167\end{array}$ & $<.001$ & $\begin{array}{l}\text { Age } 60+=53.15 \\
\text { LSE }=88.71 \\
\text { PL }=85.50 \\
\text { GSI }=95.32\end{array}$ & $\begin{array}{l}\text { Age } 60+\text { use SM in their } \\
\text { private lives significantly } \\
\text { less than: } \\
\text { - LSE } \\
\text { - PL } \\
\text { - GSI }\end{array}$ \\
\hline & $\begin{array}{l}\text { I regularly } \\
\text { post } \\
\text { messages on } \\
\text { SM such as } \\
\text { Twitter, } \\
\text { Facebook or } \\
\text { Instagram } \\
\end{array}$ & $\begin{array}{l}12.228,3, \\
167\end{array}$ & .007 & $\begin{array}{l}\text { Age } 60+=57.32 \\
\text { LSE }=91.78 \\
\text { PL }=89.60 \\
\text { GSI }=87.99\end{array}$ & $\begin{array}{l}\text { Age } 60+\text { significantly less } \\
\text { likely to post messages on } \\
\text { SM than: } \\
\text { - LSE } \\
\text { - GSI }\end{array}$ \\
\hline & $\begin{array}{l}\text { Most of my } \\
\text { friends use } \\
\text { SM to keep } \\
\text { in touch }\end{array}$ & $\begin{array}{l}16.553,3, \\
167\end{array}$ & .001 & $\begin{array}{l}\text { Age } 60+=59.43 \\
\text { LSE }=85.96 \\
\text { PL }=76.35 \\
\text { GSI }=99.03\end{array}$ & $\begin{array}{l}\text { Age } 60+\text { significantly less } \\
\text { likely to perceive their } \\
\text { friends use SM to stay in } \\
\text { touch than: } \\
\text { - LSE } \\
\text { - GSI }\end{array}$ \\
\hline & $\begin{array}{l}\text { Emergency } \\
\text { services } \\
\text { should not } \\
\text { trust } \\
\text { information } \\
\text { on SM† }\end{array}$ & $\begin{array}{l}12.390,3, \\
167\end{array}$ & .006 & $\begin{array}{l}\text { Age } 60+=71.15 \\
\text { LSE }=75.22 \\
\text { PL }=81.02 \\
\text { GSI }=101.35\end{array}$ & $\begin{array}{l}\text { GSI respondents have } \\
\text { significantly more positive } \\
\text { attitude towards emergency } \\
\text { services trusting information } \\
\text { on SM than: } \\
\text { - Age 60+ } \\
\text { - LSE }\end{array}$ \\
\hline
\end{tabular}

Table A2. Kruskal-Wallis H test and post hoc paired Mann-Whitney test analyses of 
vulnerability type by measures of SM use and trust towards SM

\begin{tabular}{|c|c|c|c|c|c|}
\hline $\begin{array}{l}\text { Independent } \\
\text { variable }\end{array}$ & $\begin{array}{l}\text { Dependent } \\
\text { variable }\end{array}$ & $\begin{array}{l}\text { Kruskal-Wallis } \mathrm{H} \\
\text { test } \chi^{2}, d f \text {, and } n\end{array}$ & $p$-value & $\begin{array}{l}\text { Mean rank for each } \\
\text { vulnerability type }\end{array}$ & $\begin{array}{l}\text { Post hoc paired Mann- } \\
\text { Whitney test }(p<.05)^{*}\end{array}$ \\
\hline \multirow[t]{2}{*}{$\begin{array}{l}\text { Vulnerability } \\
\text { type (i.e., aged } \\
60+, \text { LSE, PL or } \\
\text { GSI) }\end{array}$} & $\begin{array}{l}\text { Awareness of } \\
\text { safety service } \\
\text { provided by } \\
\text { Twitter alerts' }\end{array}$ & $19.810,3,167$ & k.001 & $\begin{array}{l}\text { Age } 60+=53.85 \\
\text { LSE }=83.31 \\
\mathrm{PL}=83.98 \\
\text { GSI }=101.15\end{array}$ & $\begin{array}{l}\text { Age } 60+\text { significantly less } \\
\text { likely to be aware of } \\
\text { Twitter alerts' than: } \\
\text { - GSI } \\
\text { - LSE }\end{array}$ \\
\hline & $\begin{array}{l}\text { Awareness of } \\
\text { safety service } \\
\text { provided by } \\
\text { Facebook } \\
\text { safety checks' }\end{array}$ & $18.724,3,167$ & k.001 & $\begin{array}{l}\text { Age } 60+=55.58 \\
\text { LSE }=95.60 \\
\text { PL }=71.33 \\
\text { GSI }=93.68\end{array}$ & $\begin{array}{l}\text { Age } 60+\text { significantly less } \\
\text { likely to be aware of } \\
\text { Facebook safety checks' } \\
\text { than: } \\
\text { - GSI } \\
\text { - LSE }\end{array}$ \\
\hline
\end{tabular}

Table A3. Kruskal-Wallis $H$ test and post hoc paired Mann-Whitney test analyses of vulnerability type by awareness of Twitter alerts and Facebook safety checks

Note: (i) *Significance values have been adjusted by the Bonferroni correction for multiple tests

\begin{tabular}{|c|c|c|c|c|c|}
\hline $\begin{array}{l}\text { Independent } \\
\text { variable }\end{array}$ & $\begin{array}{l}\text { Dependent } \\
\text { variable }\end{array}$ & $\begin{array}{l}\text { Kruskal- } \\
\text { Wallis } \mathrm{H} \\
\text { test } \chi^{2}, d f \text {, } \\
\text { and } n\end{array}$ & $\begin{array}{l}p \text { - } \\
\text { value }\end{array}$ & $\begin{array}{l}\text { Mean rank for each } \\
\text { vulnerability type }\end{array}$ & $\begin{array}{l}\text { Post hoc paired Mann- } \\
\text { Whitney test }(p<.05)^{*}\end{array}$ \\
\hline \multirow[t]{3}{*}{$\begin{array}{l}\text { Vulnerability } \\
\text { type (i.e., aged } \\
60+, \text { LSE, PL or } \\
\text { GSI) }\end{array}$} & $\begin{array}{l}\text { Helpfulness } \\
\text { of } \\
\text { information } \\
\text { sought via } \\
\text { SM from } \\
\text { emergency } \\
\text { response } \\
\text { organisation } \\
\text { s (e.g. police, } \\
\text { fire brigade) }\end{array}$ & $\begin{array}{l}11.706,3, \\
167\end{array}$ & .008 & $\begin{array}{l}\text { Age } 60+=83.87 \\
\text { LSE }=72.46 \\
\text { PL }=67.87 \\
\text { GSI }=97.30\end{array}$ & $\begin{array}{l}\text { GSI rated perceived } \\
\text { helpfulness of information } \\
\text { sought via SM from EROs } \\
\text { significantly higher than: } \\
\text { - LSE } \\
\text { - PL }\end{array}$ \\
\hline & $\begin{array}{l}\text { Helpfulness } \\
\text { of } \\
\text { information } \\
\text { sought via } \\
\text { SM from } \\
\text { local } \\
\text { community } \\
\text { groups (e.g. } \\
\text { Grey } \\
\text { Nomads, } \\
\text { Surf clubs) }\end{array}$ & $\begin{array}{l}10.509,3, \\
167\end{array}$ & .015 & $\begin{array}{l}\text { Age } 60+=60.55 \\
\text { LSE }=70.94 \\
\text { PL }=48.29 \\
\text { GSI }=79.26\end{array}$ & $\begin{array}{l}\text { GSI rated perceived } \\
\text { helpfulness of information } \\
\text { sought via SM from local } \\
\text { community groups } \\
\text { significantly higher than: } \\
\text { - PL }\end{array}$ \\
\hline & $\begin{array}{l}\text { Helpfulness } \\
\text { of } \\
\text { information } \\
\text { sought via } \\
\text { SM from } \\
\text { local online } \\
\text { groups (e.g. } \\
\text { Twitter feed } \\
\text { or Facebook } \\
\text { page of local } \\
\text { community } \\
\text { group) }\end{array}$ & $\begin{array}{l}9.202,3 \\
167\end{array}$ & .027 & $\begin{array}{l}\text { Age } 60+=69.98 \\
\text { LSE }=84.06 \\
\text { PL }=59.88 \\
\text { GSI }=88.78\end{array}$ & $\begin{array}{l}\text { GSI rated perceived } \\
\text { helpfulness of information } \\
\text { sought via SM from local } \\
\text { online groups significantly } \\
\text { higher than: } \\
\text { - PL }\end{array}$ \\
\hline
\end{tabular}

Table A4. Kruskal-Wallis $H$ test and post hoc paired Mann-Whitney test analyses of vulnerability type 
by perceived helpfulness of information about extreme weather events sought via SM from different organisations

Note: (i) *Significance values have been adjusted by the Bonferroni correction for multiple tests

\begin{tabular}{|c|c|c|c|c|c|}
\hline $\begin{array}{l}\text { Independent } \\
\text { variable }\end{array}$ & $\begin{array}{l}\text { Dependent } \\
\text { variable }\end{array}$ & $\begin{array}{l}\text { Kruskal- } \\
\text { Wallis } \mathrm{H} \text { test } \\
\chi^{2}, d f \text {, and } n\end{array}$ & $\begin{array}{l}p \text { - } \\
\text { value }\end{array}$ & $\begin{array}{l}\text { Mean rank for each } \\
\text { vulnerability type }\end{array}$ & $\begin{array}{l}\text { Post hoc paired Mann- } \\
\text { Whitney test }(p<.05)^{*}\end{array}$ \\
\hline $\begin{array}{l}\text { Vulnerability } \\
\text { type (i.e., aged } \\
60+, \text { LSE, PL } \\
\text { or GSI) }\end{array}$ & $\begin{array}{l}\text { How likely are } \\
\text { you to use SM } \\
\text { in the future to } \\
\text { look for } \\
\text { information as } \\
\text { a result of an } \\
\text { extreme } \\
\text { weather event } \\
\text { such as a } \\
\text { flood, storm, } \\
\text { fire or } \\
\text { heatwave? }\end{array}$ & $12.666,3,167$ & .005 & $\begin{array}{l}\text { Age } 60+=64.85 \\
\text { LSE }=94.19 \\
\text { PL }=71.23 \\
\text { GSI }=90.18\end{array}$ & $\begin{array}{l}\text { Age } 60+\text { significantly } \\
\text { less likely to perceive } \\
\text { they'll seek information } \\
\text { from SM in the future } \\
\text { than: } \\
\text { - LSE }\end{array}$ \\
\hline
\end{tabular}

Table A5. Kruskal-Wallis $H$ test and post hoc paired Mann-Whitney test analyses of vulnerability type by likelihood of using SM in the future to obtain information about extreme weather events

Note: (i) *Significance values have been adjusted by the Bonferroni correction for multiple tests

\begin{tabular}{|c|c|c|c|c|c|}
\hline $\begin{array}{l}\text { Independent } \\
\text { variable }\end{array}$ & $\begin{array}{l}\text { Dependent } \\
\text { variable }\end{array}$ & $\begin{array}{l}\text { Kruskal- } \\
\text { Wallis } \mathrm{H} \\
\text { test } \chi^{2}, d f \text {, } \\
\text { and } n\end{array}$ & $p$-value & $\begin{array}{l}\text { Mean rank for each } \\
\text { vulnerability type }\end{array}$ & $\begin{array}{l}\text { Post hoc paired Mann- } \\
\text { Whitney test }(p<.05)^{*}\end{array}$ \\
\hline \multirow[t]{2}{*}{$\begin{array}{l}\text { Vulnerability } \\
\text { type (i.e., aged } \\
60+, \text { LSE, PL } \\
\text { or GSI) }\end{array}$} & $\begin{array}{l}\text { People } \\
\text { prefer to } \\
\text { look for } \\
\text { informatio } \\
\mathrm{n} \text { via SM } \\
\text { rather than } \\
\mathrm{TV} \text {, radio } \\
\text { or } \\
\text { traditional } \\
\text { websites } \\
\text { because } \\
\text { the } \\
\text { informatio } \\
\mathrm{n} \text { is } \\
\text { available } \\
\text { faster }\end{array}$ & $27.028,3,167$ & $<.001$ & $\begin{array}{l}\text { Age } 60+=51.75 \\
\text { LSE }=93.17 \\
\text { PL }=70.00 \\
\text { GSI }=98.87\end{array}$ & $\begin{array}{l}\text { LSE and GSI significantly } \\
\text { more likely to think people } \\
\text { prefer to look for } \\
\text { information on SM because } \\
\text { it is faster than: } \\
\text { - } 60+ \\
\text { LSE significantly more } \\
\text { likely to think people } \\
\text { prefer to look for } \\
\text { information on SM because } \\
\text { it is faster than: } \\
\text { - PL }\end{array}$ \\
\hline & $\begin{array}{l}\text { People } \\
\text { prefer to } \\
\text { look for } \\
\text { informatio } \\
\mathrm{n} \text { via SM } \\
\text { rather than } \\
\mathrm{TV} \text {, radio } \\
\text { or } \\
\text { traditional } \\
\text { websites } \\
\text { because }\end{array}$ & $21.213,3,167$ & $<.001$ & $\begin{array}{l}\text { Age } 60+=61.35 \\
\text { LSE }=98.09 \\
\text { PL }=62.31 \\
\text { GSI }=92.26\end{array}$ & $\begin{array}{l}\text { LSE and GSI significantly } \\
\text { more likely to think people } \\
\text { prefer to look for } \\
\text { information on SM because } \\
\text { it is more accessible than: } \\
\text { - } 60+ \\
\text { - PL }\end{array}$ \\
\hline
\end{tabular}




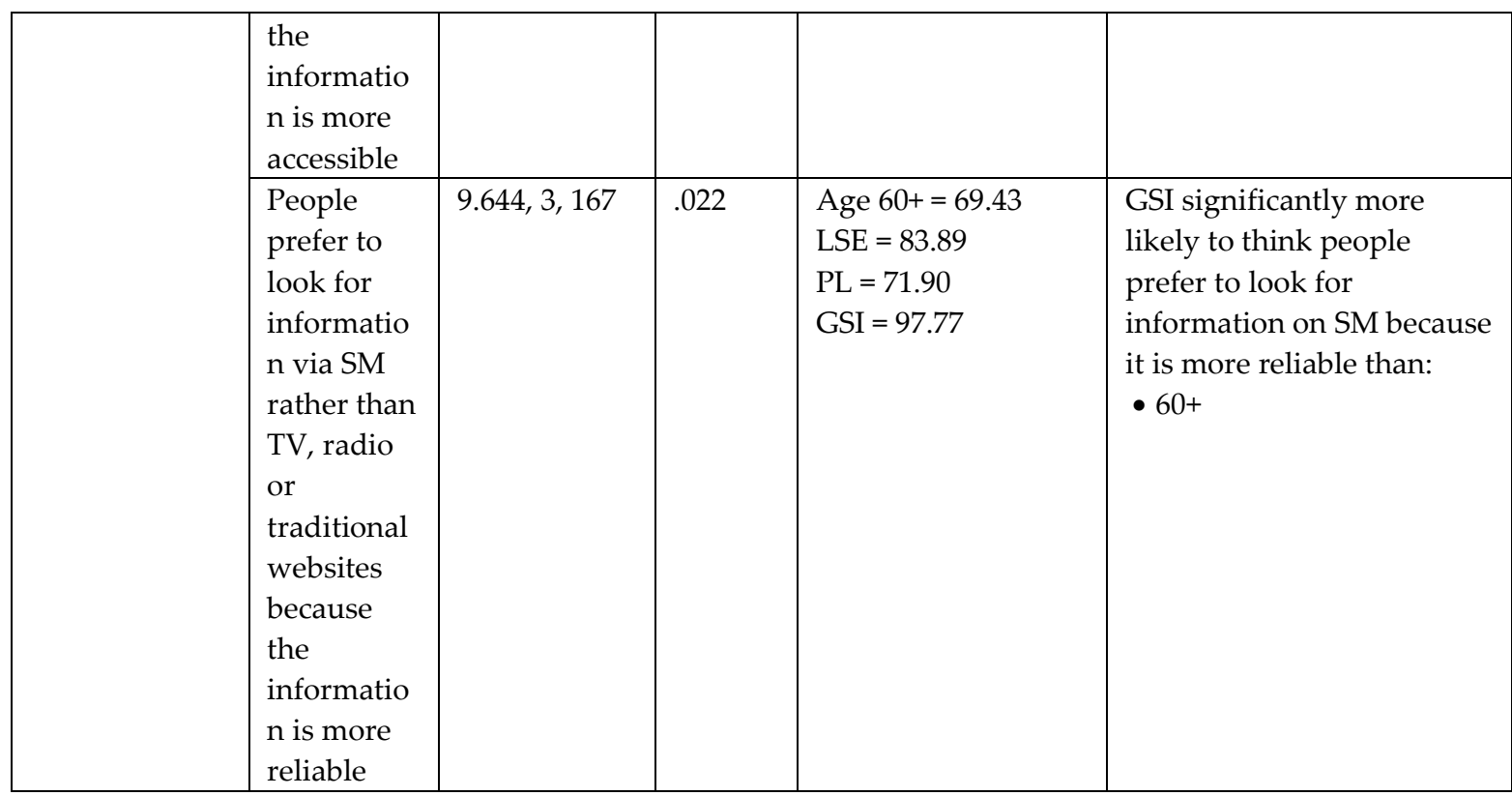

Table A6. Kruskal-Wallis H test and post hoc paired Mann-Whitney test analyses of vulnerability type by perceived reasons people prefer to look for information via SM compared to other information sources

Note: (i) *Significance values have been adjusted by the Bonferroni correction for multiple tests

\begin{tabular}{|c|c|c|c|c|c|}
\hline $\begin{array}{l}\text { Independe } \\
\text { nt variable }\end{array}$ & $\begin{array}{l}\text { Dependent } \\
\text { variable }\end{array}$ & $\begin{array}{l}\text { Kruskal-Wallis } \\
H \text { test } \chi^{2}, d f \text {, and } \\
n\end{array}$ & $\begin{array}{l}p \text { - } \\
\text { value }\end{array}$ & $\begin{array}{l}\text { Mean rank for each } \\
\text { vulnerability type }\end{array}$ & $\begin{array}{l}\text { Post hoc paired Mann- } \\
\text { Whitney test }(p<.05)^{*}\end{array}$ \\
\hline \multirow[t]{3}{*}{$\begin{array}{l}\text { Vulnerabili } \\
\text { ty type } \\
\text { (i.e., aged } \\
60+, \text { LSE, } \\
\text { PL or GSI) }\end{array}$} & $\begin{array}{l}\text { Emergency } \\
\text { services should } \\
\text { regularly } \\
\text { monitor their } \\
\text { SM so they can } \\
\text { promptly } \\
\text { respond to } \\
\text { urgent requests } \\
\text { for help. }\end{array}$ & $16.208,3,167$ & .001 & $\begin{array}{l}\text { Age } 60+=55.38 \\
\text { LSE }=88.45 \\
\text { PL }=82.17 \\
\text { GSI }=95.95\end{array}$ & $\begin{array}{l}\text { GSI and LSE } \\
\text { significantly more } \\
\text { likely to think } \\
\text { emergency services } \\
\text { should regularly } \\
\text { monitor their SM than: } \\
\text { - Age 60+ }\end{array}$ \\
\hline & $\begin{array}{l}\text { If I posted an } \\
\text { urgent request } \\
\text { for help on the } \\
\text { SM site of a local } \\
\text { ERO I would } \\
\text { expect to get a } \\
\text { response from } \\
\text { them within an } \\
\text { hour. }\end{array}$ & $9.332,3,167$ & .025 & $\begin{array}{l}\text { Age } 60+=71.20 \\
\text { LSE }=86.84 \\
\text { PL }=67.46 \\
\text { GSI }=95.91\end{array}$ & $\begin{array}{l}\text { - No significant } \\
\text { pairwise differences }\end{array}$ \\
\hline & $\begin{array}{l}\text { Emergency } \\
\text { services are too } \\
\text { busy to monitor } \\
\text { SM during an } \\
\text { emergency. }\end{array}$ & $8.056,3,167$ & .045 & $\begin{array}{l}\text { Age } 60+=82.18 \\
\text { LSE }=73.33 \\
\text { PL }=80.08 \\
\text { GSI }=97.71\end{array}$ & $\begin{array}{l}\text { GSI significantly more } \\
\text { likely to think } \\
\text { emergency services are } \\
\text { too busy to monitor SM } \\
\text { than: } \\
\text { - LSE }\end{array}$ \\
\hline
\end{tabular}

Table A7. Kruskal-Wallis H test and post hoc paired Mann-Whitney test analyses of vulnerability type by expectations of emergency services' use of SM

Note: (i) *Significance values have been adjusted by the Bonferroni correction for multiple tests

\begin{tabular}{|l|l|l|l|l|l|}
\hline Independent & Dependent & Kruskal- & $p$-value & Mean rank for each & Post hoc paired Mann- \\
\hline
\end{tabular}




\begin{tabular}{|c|c|c|c|c|c|}
\hline variable & variable & $\begin{array}{l}\text { Wallis } H \text { test } \\
\chi^{2}, d f \text {, and } n\end{array}$ & & vulnerability type & Whitney test $(p<.05)^{*}$ \\
\hline \multirow[t]{3}{*}{$\begin{array}{l}\text { Vulnerability } \\
\text { type (i.e., aged } \\
60+, \text { LSE, PL } \\
\text { or GSI) }\end{array}$} & $\begin{array}{l}\text { Information } \\
\text { on SM from } \\
\text { emergency } \\
\text { services } \\
\text { organisations } \\
\text { meets my } \\
\text { needs }\end{array}$ & $14.886,3,167$ & .002 & $\begin{array}{l}\text { Age } 60+=63.13 \\
\text { LSE }=86.97 \\
\text { PL }=70.17 \\
\text { GSI }=98.19\end{array}$ & $\begin{array}{l}\text { GSI significantly more } \\
\text { likely to think } \\
\text { information on SM } \\
\text { from ESOs meets their } \\
\text { needs than: } \\
\text { - Age 60+ } \\
\text { - PL }\end{array}$ \\
\hline & $\begin{array}{l}\text { My } \\
\text { information } \\
\text { needs during } \\
\text { extreme } \\
\text { weather } \\
\text { events are } \\
\text { very specific }\end{array}$ & $18.273,3,167$ & $<.001$ & $\begin{array}{l}\text { Age } 60+=64.00 \\
\text { LSE }=80.84 \\
\text { PL }=71.96 \\
\text { GSI }=103.82\end{array}$ & $\begin{array}{l}\text { GSI significantly more } \\
\text { likely to think their } \\
\text { information needs } \\
\text { during extreme } \\
\text { weather event are very } \\
\text { specific than: } \\
\text { - Age 60+ } \\
\text { - LSE } \\
\text { - PL } \\
\end{array}$ \\
\hline & $\begin{array}{l}\text { I get most } \\
\text { information } \\
\text { related to } \\
\text { my specific } \\
\text { situation } \\
\text { offline rather } \\
\text { than through } \\
\text { SM during } \\
\text { extreme } \\
\text { weather } \\
\text { events }\end{array}$ & $9.043,3,167$ & .029 & $\begin{array}{l}\text { Age } 60+=74.48 \\
\text { LSE }=82.30 \\
P L=68.88 \\
\text { GSI }=98.06\end{array}$ & $\begin{array}{l}\text { - No significant } \\
\text { pairwise differences }\end{array}$ \\
\hline
\end{tabular}

Table A8. Kruskal-Wallis $H$ test and post hoc paired Mann-Whitney test analyses of vulnerability type by participant's information needs during extreme weather events

Note: (i) *Significance values have been adjusted by the Bonferroni correction for multiple tests

Copyright: (c) 2022 authors. This is an open-access article distributed under the terms of the Creative Commons Attribution-NonCommercial 3.0 Australia License, which permits noncommercial use, distribution, and reproduction in any medium, provided the original author and AJIS are credited.

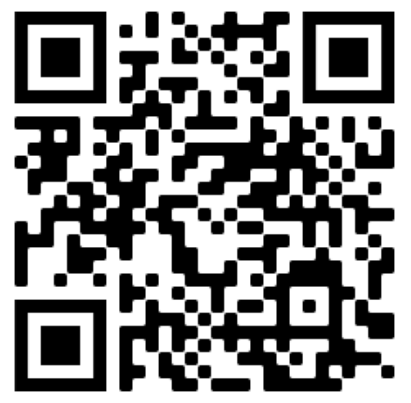

